\title{
El Niño-Southern Oscillation related fluctuations of the marine carbon cycle
}

\author{
A. M. E. Winguth, M. Heimann, K. D. Kurz, E. Maier-Reimer, \\ U. Mikolajewicz, and J. Segschneider \\ Max-Planck-Institut für Meteorologie, Hamburg, Germany
}

\begin{abstract}
We investigate the response of a three-dimensional ocean circulation model (Hamburg LSG) coupled on-line with an oceanic carbon cycle model (HAMOCC-3) to El Niño-Southern Oscillation (ENSO) induced fluctuations of the wind field. During El Niño 1982/1983, when upwelling and biological productivity in the equatorial Pacific were strongly reduced and sea surface temperatures were increased, the oceanic $\mathrm{CO}_{2}$ partial pressure in this region decreased significantly. Consequently, in 1982/1983 the $\mathrm{CO}_{2}$ flux from the tropical ocean into the atmosphere was reduced. However, in 1983 the interannual deviations from the long-term trend in atmospheric $\mathrm{CO}_{2}$ showed in January low and in December high values with a total shift by more then $1.4 \mathrm{GtC}$. The model simulation supports the oceanic measurements and predicts a temporary uptake of $0.6 \mathrm{GtC}$ during the ENSO year 1983. We conclude that the concurrent release of $\mathrm{CO}_{2}$ from the land biosphere must have been about $2 \mathrm{GtC}$.
\end{abstract}

\section{Introduction}

The mean global growth rate of atmospheric $\mathrm{CO}_{2}$ from mid-1970s to mid-1980s has been estimated by Gammon et al. [1985] $1.4 \mathrm{ppm} /$ year, which is mainly caused by a nearly constant fossil fuel burning of approximately $5 \mathrm{GtC}$ during that period. The year-toyear increase in the atmospheric $\mathrm{CO}_{2}$ concentration is, however, not constant and fluctuates around the mean growth rate. Bacastow [1976] first compared the $\mathrm{CO}_{2}$ fluctuations with the El Niño-Southern Oscillation (ENSO) events in the Pacific, one of the most significant climate variations on a timescale of 2-7 years. The El Niño events are characterized by reduced upwelling and an anomalous increase of the sea surface temperature (SST) in the entire equatorial Pacific [Rasmusson and Wallace, 1983]. The minima of the Southern Oscillation index (SOI, defined as sea level pressure difference between Darwin, Australia, and Tahiti, French Polynesia normalized by the standard deviation), are correlated with peaks of the $\mathrm{CO}_{2}$ record with a time lag of 1-7 months [Bacastow, 1976; Bacastow et al., 1980]. The most remarkable ENSO of this century started in 1982 with a strong decline of the SOI in June (Figure 1). Almost in phase with this decline a decrease

Copyright 1994 by the American Geophysical Union.

Paper number 93GB03134.

0886-6236/94/93GB-03134\$10.00 of $-0.7 \mathrm{ppm} / \mathrm{yr}$ in the anomaly of the long-term atmospheric $\mathrm{CO}_{2}$ growth rate has been observed. The negative anomaly of the $\mathrm{CO}_{2}$ growth rate vanished in late 1982 and reached in the following spring 1983 an extreme strong maximum of $1.8 \mathrm{ppm} / \mathrm{yr}$. Several previous investigators focused interpretations on the oceanic effects to explain the anomalous atmospheric $\mathrm{CO}_{2}$ drop in 1982 and rise in 1983. Newell et al. [1978] and Machta et al. [1977] suggested that in El Niño periods the increase of atmospheric $\mathrm{CO}_{2}$ partial pressure $\left(\mathrm{pCO}_{2}\right)$ is related to enhanced outgassing of $\mathrm{CO}_{2}$ induced by lower solubilities produced by the anomalously high SST. On the basis of the observed reduction of the oceanic primary production, several authors [Chavez, 1984;Gammon et al., 1985] have argued that the 1983 peak in the anomaly of the $\mathrm{CO}_{2}$ growth rate might be explained by the reductions in nutrient supply due to a weaker equatorial upwelling.

The $\mathrm{CO}_{2}$ flux from the equatorial oceans into the atmosphere in early 1980s has been estimated by Keeling and Revelle [1985] to be $2 \mathrm{GtC} / \mathrm{yr}$, which is about $40 \%$ of the anthropogenic input from fossil fuel burnings. In non-El Niño years the Eastern Equatorial Pacific (EEP) dominates with $0.6 \mathrm{GtC}$, whereas in early 1983 during the extreme phase of the El Niño the atmosphere and EEP were almost in balance [Keeling and Revelle, 1985; Feely et al., 1987]. Measurements in the EEP during El Niño 1986/1988 [Inoue and Sugimura, 1992; Wong et al., 1993] supported the suggestions that during El Niño periods, when the upwelling of cold carbon-rich wa- 


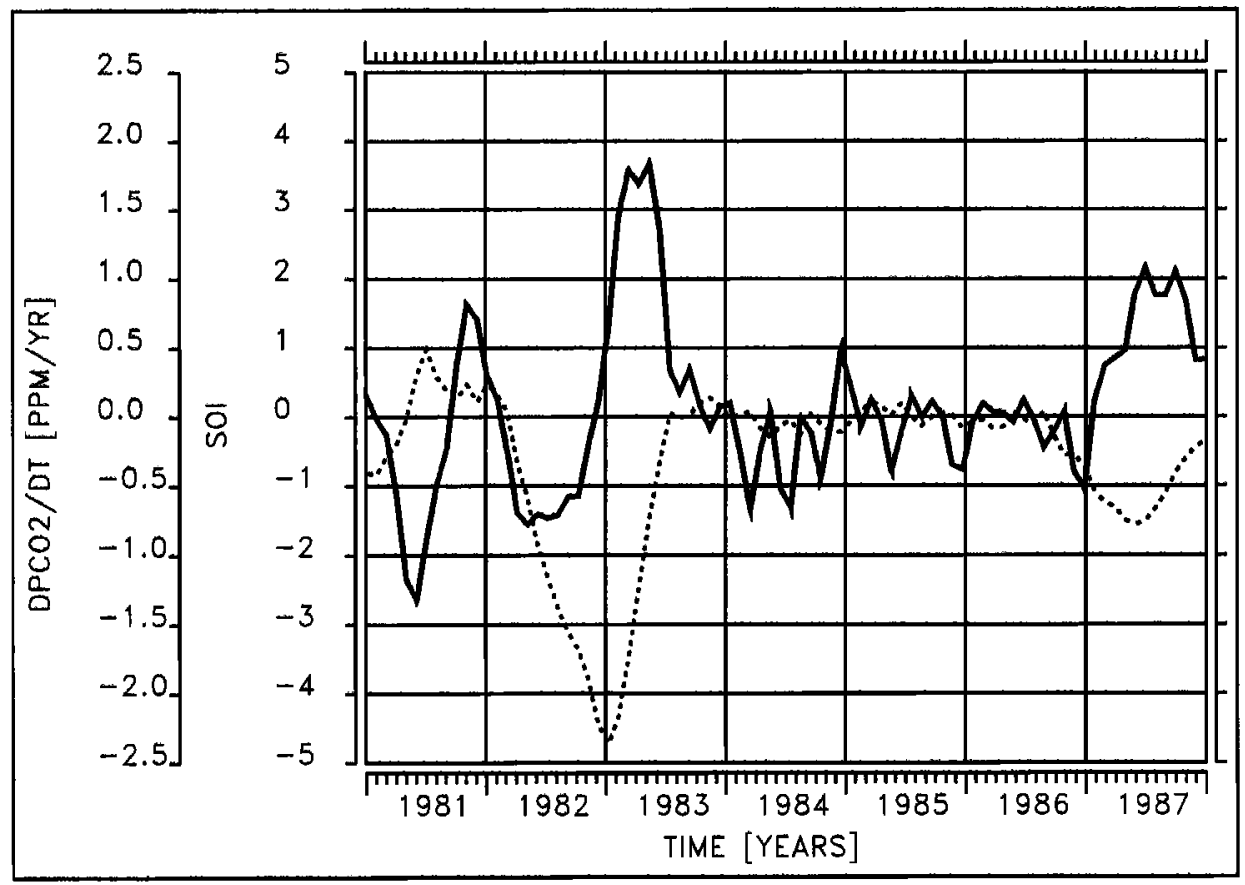

Figure 1. Time series of the 5-month running mean of the difference between the standardized sea level pressure anomalies at Tahiti and Darwin (SOI) (dashed line) after $P$. W. Wright [personal communication, 1984]. Values are standardized by the mean annual standard deviation. The solid line indicates the 5-month running mean of the deviations from the long-term atmospheric $\mathrm{CO}_{2}$ growth rate, calculated by centered finite differences from the anomaly in the $\mathrm{CO}_{2}$ concentration after Keeling et al. [1989, Figure 20, p. 180]. The anomaly is computed by averaging the $\mathrm{CO}_{2}$ concentrations of Mauna Loa and the South Pole after subtraction of the seasonal variations and the man-made secular trend from the observational records. The average of the two records can be assumed to represent a global mean.

ter from deeper layers is strongly reduced, the oceanic $\mathrm{pCO}_{2}$ is substantially decreased. A reduced $\mathrm{CO}_{2}$ outgassing from the eastern equatorial Pacific into the atmosphere would cause a negative anomaly in the $\mathrm{CO}_{2}$ growth rate and not explain the peak in early 1983.

The work of Gammon et al. [1985] estimated for late 1982 a global atmospheric growth rate of $0.0 \pm 0.3$ $\mathrm{ppm} / \mathrm{yr}$. This value is well below the mean global atmospheric growth rate $1.4 \mathrm{ppm} / \mathrm{yr}$. In a detailed analysis of the atmospheric records from 24 stations of the NOAA/GMCC program (National Oceanic and Atmospheric Administration/Geophysical Monitoring for Climatic Change) the authors suggested that extra tropical $\mathrm{CO}_{2}$ sinks in the northern and southern hemisphere were intensified in late 1982 [see Gammon et al., 1985, Figure 3.20(B)].

In the southern high latitudes the $\mathrm{CO}_{2}$ sink might be explained by an oceanic carbon uptake. The authors suggested that other effects, such as changes in the land biosphere or direct radiative effects of stratospheric cooling by the dust from the March-April 1982 eruptions of the El Chichon, Mexico, could not have been responsible for the observed $\mathrm{CO}_{2}$ retardation of the increase.
The interpretation of the sink in the northern hemisphere in late 1982 is more complicated due to superposition of oceanic fluctuations with volcanic and land biosphere effects. Gammon et al. [1985] proposed a possible teleconnection between the northern subtropical and the southern subantarctic latitudes. This connection would be not consistent with the concept of equatorially generated $\mathrm{CO}_{2}$ perturbations. Nevertheless, calculations of the $\mathrm{CO}_{2}$ growth rate from the Keeling et al. record (Figure 1) do not indicate a strong decline of the growth rate in 1982 . Thus discussions about anomalous atmospheric $\mathrm{CO}_{2}$ sources and sinks in 1982 are controversial.

The 1982 drop and 1983 rise of the anomaly of the $\mathrm{CO}_{2}$ growth rate were investigated by studies with box models of the ocean-atmosphere carbon cycle for the tropical region. Volk [1989] analyzed with three- and five-box models the effects of a strong decline of equatorial upwelling. The models reproduced the major trends during El Niño 1982/1983 for sea surface temperature, nutrients, and $\Delta \mathrm{pCO}_{2}$. The increasing temperature during El Niño with lower $\mathrm{CO}_{2}$ solubility in warmer water, has an important impact on the carbon budget. Volk estimated with the box models the impact of SST 
warming on the atmospheric $\mathrm{CO}_{2}$ growth rate. Without any warming of the sea surface the decrease in the $\mathrm{CO}_{2}$ growth rate would be approximately $40 \%$ larger. The influence of the tropical Pacific to the drop in the atmospheric $\mathrm{CO}_{2}$ growth rate was estimated by the author to be $30 \%$. Results with a four-box model from Siegenthaler and Wenk [1989] and a five-box model with realistic wind induced perturbations in the tropics [Winguth, 1992] supported essentially the findings of Volk. These box models did not include changes in the land biosphere, and hence could not explain the $1983 / 1984$ overshoot in the growth rate. Thus the strong peak in the anomaly of the atmospheric $\mathrm{CO}_{2}$ growth rate might be explained by terrestrial biospheric effects, like enhanced burning of savannas and forests in many parts of the globe during El Niño years [Keeling and Revelle, 1985; Goldammer, personal communication, 1991]. A reduced net primary productivity (NPP) caused by excessive droughts in Southeast Asia and Australia would have acted in the same direction [Keeling et al., 1989, p. 206; Siegenthaler, 1990] .

Variations in the seasonally adjusted $\delta^{13} \mathrm{C}$ records (Figure 2) provide additional constraints on the analysis of ENSO related fluctuations in the carbon cycle. During the El Niño 1982/1983 a reduction of the isotopic ratio of atmospheric $\mathrm{CO}_{2}$ was observed in the combined South Pole and Mauna Loa records by Keeling et al. $[1989$, p. 181]. These authors suggested that the observed decrease of about $0.1 \%$ in the atmosphere must have been created by a $\mathrm{CO}_{2}$ release from the terrestrial biosphere with low $\delta^{13} \mathrm{C}$ values of approximately $-25 \%$, more than $17 \%$ lower as the $-7.6 \%$ of atmo- spheric $\mathrm{CO}_{2}$ in 1980 (Figure 2). The relation of this $17 \%$ difference in $\delta^{13} \mathrm{C}$ to an atmospheric $\mathrm{CO}_{2}$ level of $340 \mathrm{ppm}$ gives a crude estimate that $1 \mathrm{ppm}$ of $\mathrm{CO}_{2}$ from the terrestrial biosphere produces a decrease of approximately $0.05^{\circ} \%$ of atmospheric $\delta^{13} \mathrm{C}$. In their analysis the oceanic isotopic contribution to the El Niño signal due to the kinetic fractionation of the isotopic composition by the gas exchange between ocean and atmosphere was estimated to be negligible. The observed $\delta^{13} \mathrm{C}$ decline of $0.1 \%$ is approximately equivalent to a concentration increase of $2 \mathrm{ppm}$ of biospheric $\mathrm{CO}_{2}$ in the atmosphere, which is about 3 times as large as the observed $0.7 \mathrm{ppm}$ increase in 1983 . Keeling et al. concluded that during the 1983 event, while the terrestrial biosphere released $\mathrm{CO}_{2}$ to the atmosphere, a substantial amount of $\mathrm{CO}_{2}$ from the air was taken up simultaneously by the oceans.

However, the $\delta^{13} \mathrm{C}$ anomalies are on the order of the precision of the measuring method. The 1982/1983 measurements from Cape Grim $\left(41^{\circ} \mathrm{S}\right)$ reported by Francey et al. [1990] did not support the $\delta^{13} \mathrm{C}$ dip seen in the Keeling et al. data. A smaller isotopic shift would imply a smaller $\mathrm{CO}_{2}$ release by the land biosphere and hence a lower inferred concurrent uptake by the ocean.

In this paper we describe the response of the threedimensional ocean circulation model (Hamburg LSG) coupled on-line with a oceanic carbon cycle model (HAMOCC-3, summarized in section 2) to realistic wind and air temperature field anomalies. We focus on the marine carbon cycle and concentrate on interannual variations of carbon fluxes between ocean and atmosphere during the strong El Niño 1982/1983. In

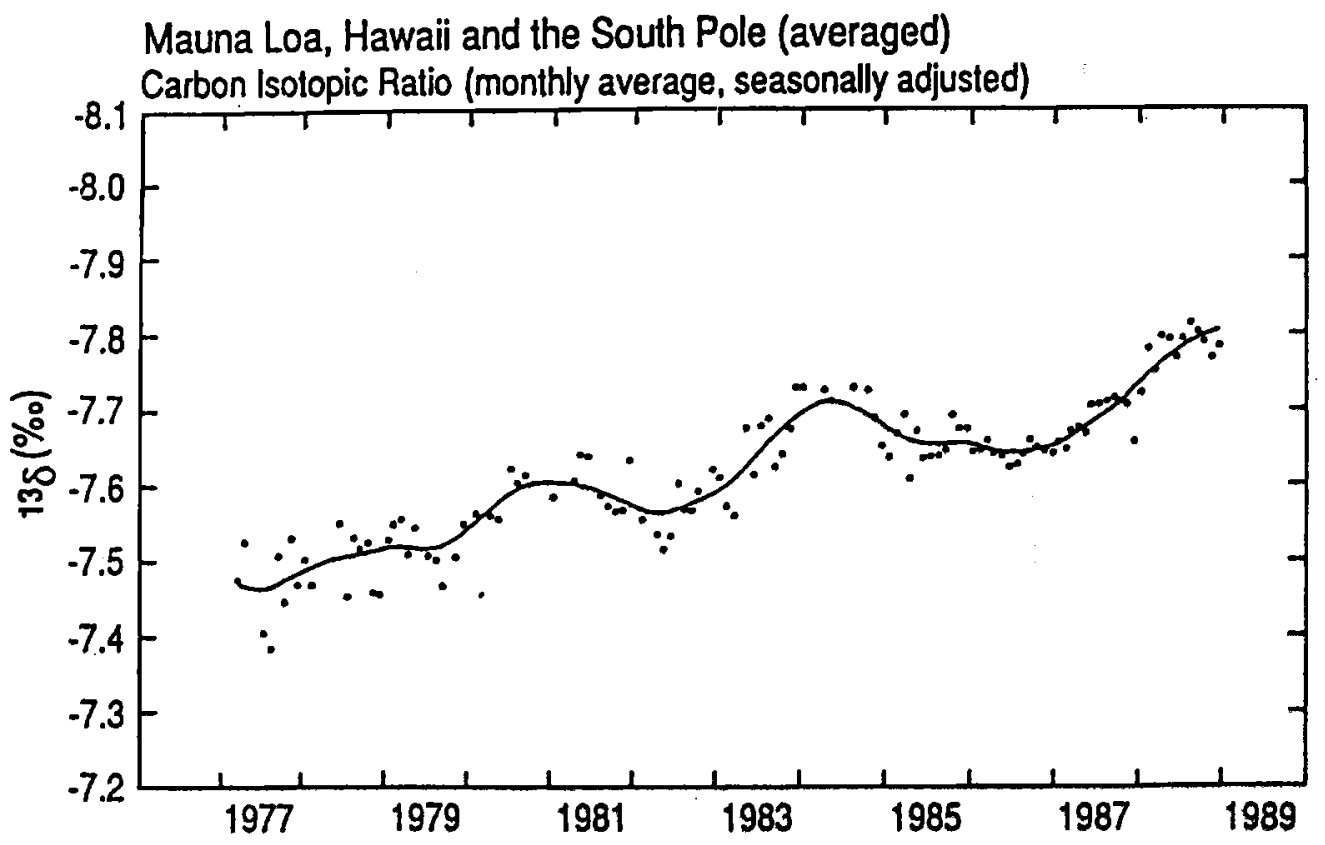

Figure 2. Seasonally adjusted record of $\delta^{13} \mathrm{C}$ of atmospheric $\mathrm{CO}_{2}$ in $\%$ : observations from Mauna Loa Observatory, Hawaii, and the South Pole combined by averaging [Keeling et al, 1989, Figure 25, p. 182]. 
particular, three main effects are considered that modify the oceanic $\mathrm{pCO}_{2}$ [Gammon et al., 1985; Keeling and Revelle, 1985; Volk, 1989]: (1) changes in the sea surface temperature; (2) changes in the upwelling velocity; and (3) changes in the marine export production (export production denotes that part of marine primary production transported into deeper layers of the ocean). A warming of the sea surface temperature causes a lower solubility and hence an increase of the oceanic $\mathrm{pCO}_{2}$.
The second and the third effect are more complex because export production is strongly coupled to the ocean circulation [Heinze et al., 1991]. Reduced upwelling of carbon-rich water decreases the oceanic $\mathrm{pCO}_{2}$. Reduced availability of nutrients would tend to decrease the primary production and hence the export of carbon by sinking organic particles. This effect counteracts the reduction of $\mathrm{pCO}_{2}$ due to the change in ocean circulation.
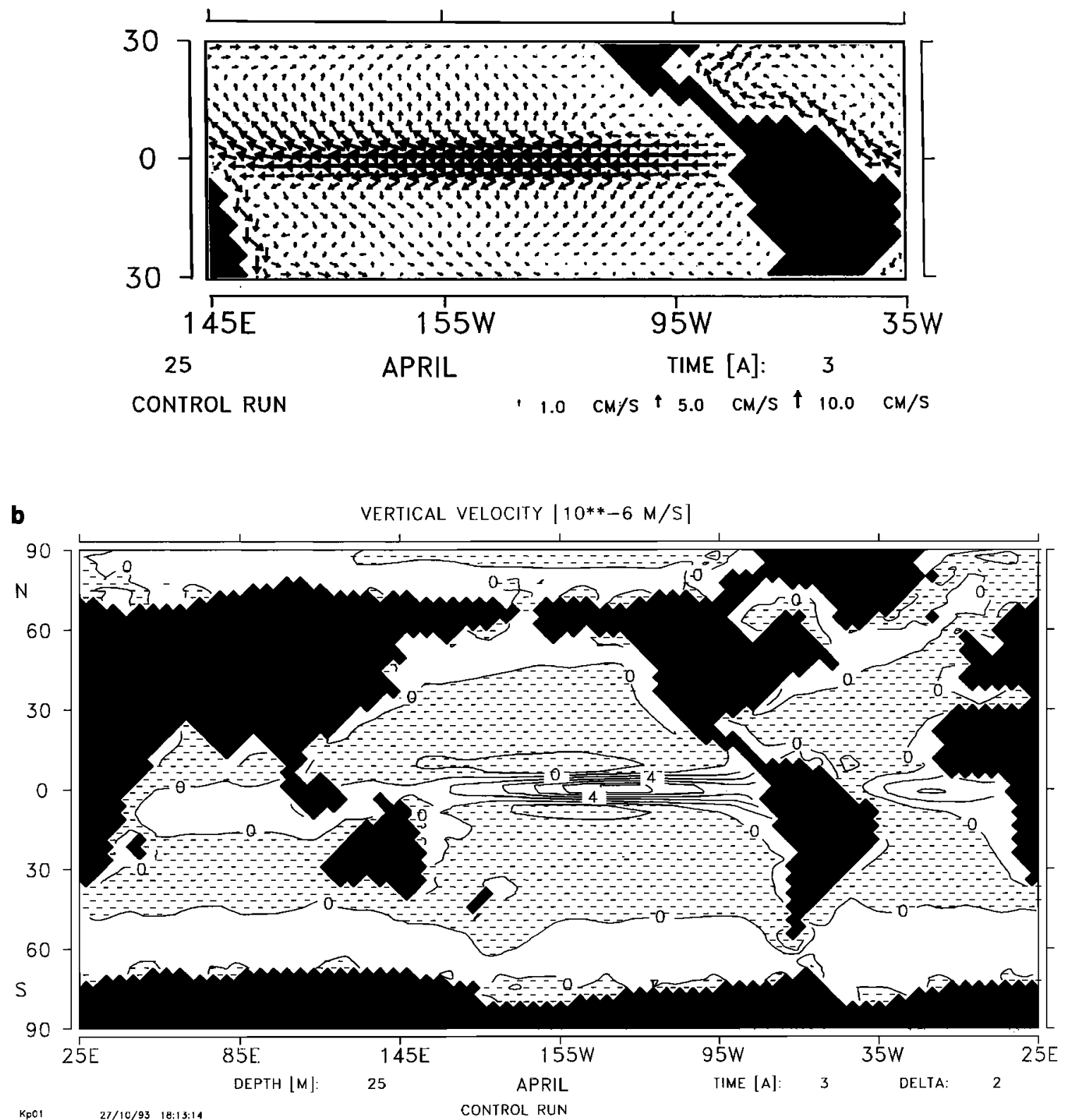

Figure 3. Control run (oceanic surface layer), April: (a) horizontal velocity of the equatorial Pacific and (b) vertical velocity (between surface and second layer, contour interval $2 \times 10^{-6} \mathrm{~m}$ $\left.\mathrm{s}^{-1}\right)$. 


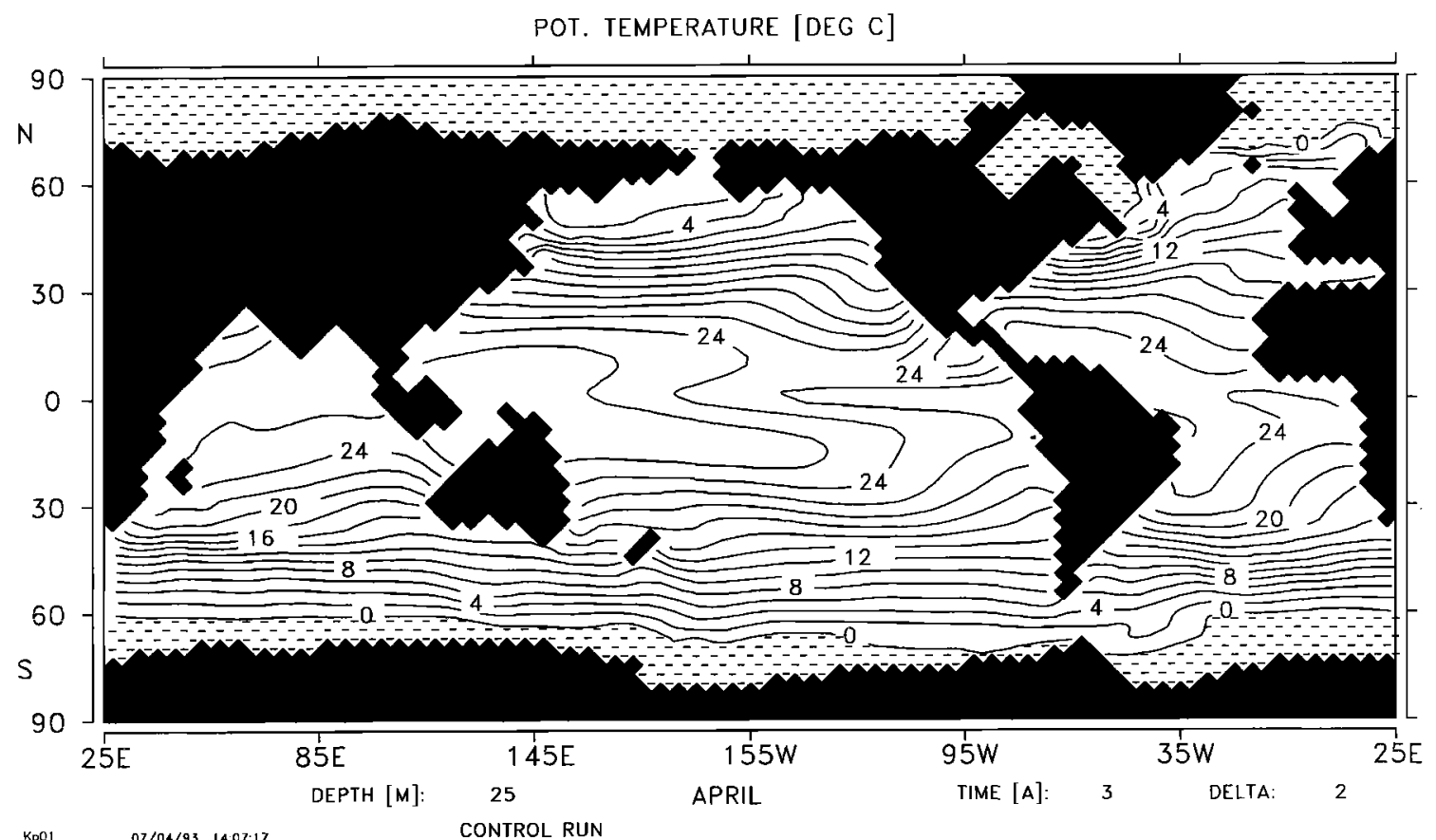

Figure 4. Control run, April: sea surface temperature (SST) (contour interval $2^{\circ} \mathrm{C}$ ).

The model was perturbed by anomalies from observed fields of wind and air temperatures analyzed for 1981-1987 at the European Center of Medium Range Weather Forecasts (ECMWF). Description of the data processing and model application is given by Segschneider [1991]. For comparison a reference run of the model was performed with climatological forcing (section 3 ). In all experiments we neglected the man-made secular increase of $\mathrm{CO}_{2}$. This simplification appears to be appropriate since the fluctuations represent only a very small perturbation of the system and the timescales do not interfere. The model includes isotopic tracers and hence can simulate interannual fluctuations of the marine $\delta^{13} \mathrm{C}$ cycle. The experiment and results of the present work are described in sections 4 and 5 , and a final summary and conclusion is given in section 6 .

\section{Model Description}

We use the three-dimensional Hamburg large-scale geostrophic (LSG) ocean general circulation model [Maier-Reimer et al., 1993] coupled on-line with the Hamburg model of the oceanic carbon cycle (HAMOCC3) [Maier-Reimer, 1993]. The following two subsections give a brief outline of the present version and present only an extension of the previously published detailed descriptions.

\section{Ocean General Circulation Model}

The model is based on the 11-layer standard version of the LSG and was run on a global $3.5^{\circ} \times 3.5^{\circ} \mathrm{E}$ grid
[Arakawa and Lamb, 1977]. Horizontal velocity and scalar components are located at depth levels 25, 75, $150,250,450,700,1000,2000,3000,4000$, and $5000 \mathrm{~m}$. A time step of 1 month is chosen to resolve the seasonal cycle.

The model version is driven by monthly mean climatologies of wind stress [Hellerman and Rosenstein, 1983], COADS air temperature [Woodruff et al., 1987], and freshwater fluxes derived from a spin up integration to climatological sea surface salinity [Levitus, 1982]. Details of the initialization are given by Mikolajewicz and Maier-Reimer [1990]. After 10,000 years of integration the model achieved a steady state. The heat flux $q_{t}$ between ocean and atmosphere is parametrized by a simple relaxation formula:

$$
q_{t}=\frac{\vartheta_{\mathrm{air}}-\vartheta}{\tau}
$$

where $\vartheta$ is the potential temperature of seawater, $\vartheta$ air is computed from an equilibrium between temperature advection in the atmosphere and prescribed data of air temperatures, and $\tau$ denotes a damping time constant, which is chosen to be 2 months.

\section{Carbon Cycle Model}

The Hamburg carbon cycle model (HAMOCC-3) is described by Maier-Reimer [1993]. Here we summarize only the aspects that are important for the present study. A seasonal cycle is included, and the distribu- 
tion of oceanic tracers is computed on-line with the circulation model. Thus interannual variability can be modeled with consideration of changes in temperaturedependent geochemical processes.

The model includes 13 prognostic tracers, of which four exchange with the atmosphere $\left(\Sigma^{12} \mathrm{CO}_{2}, \Sigma^{13} \mathrm{CO}_{2}\right.$,
$\Sigma^{14} \mathrm{CO}_{2}$, and oxygen) and six exchange with the seafloor sediment layers (the three isotopes of $\mathrm{CaCO}_{3}$ and particulate organic carbon (POC)). The other three tracers are alkalinity, phosphate, and silicate. The ${ }^{13} \mathrm{C}$ and ${ }^{14} \mathrm{C}$ isotopes are treated like ${ }^{12} \mathrm{C}$ as concentrations and transformed in the model output into the standard no-

a OCEAN-ATMOSPHERE DIFFERENCE IN PCO2

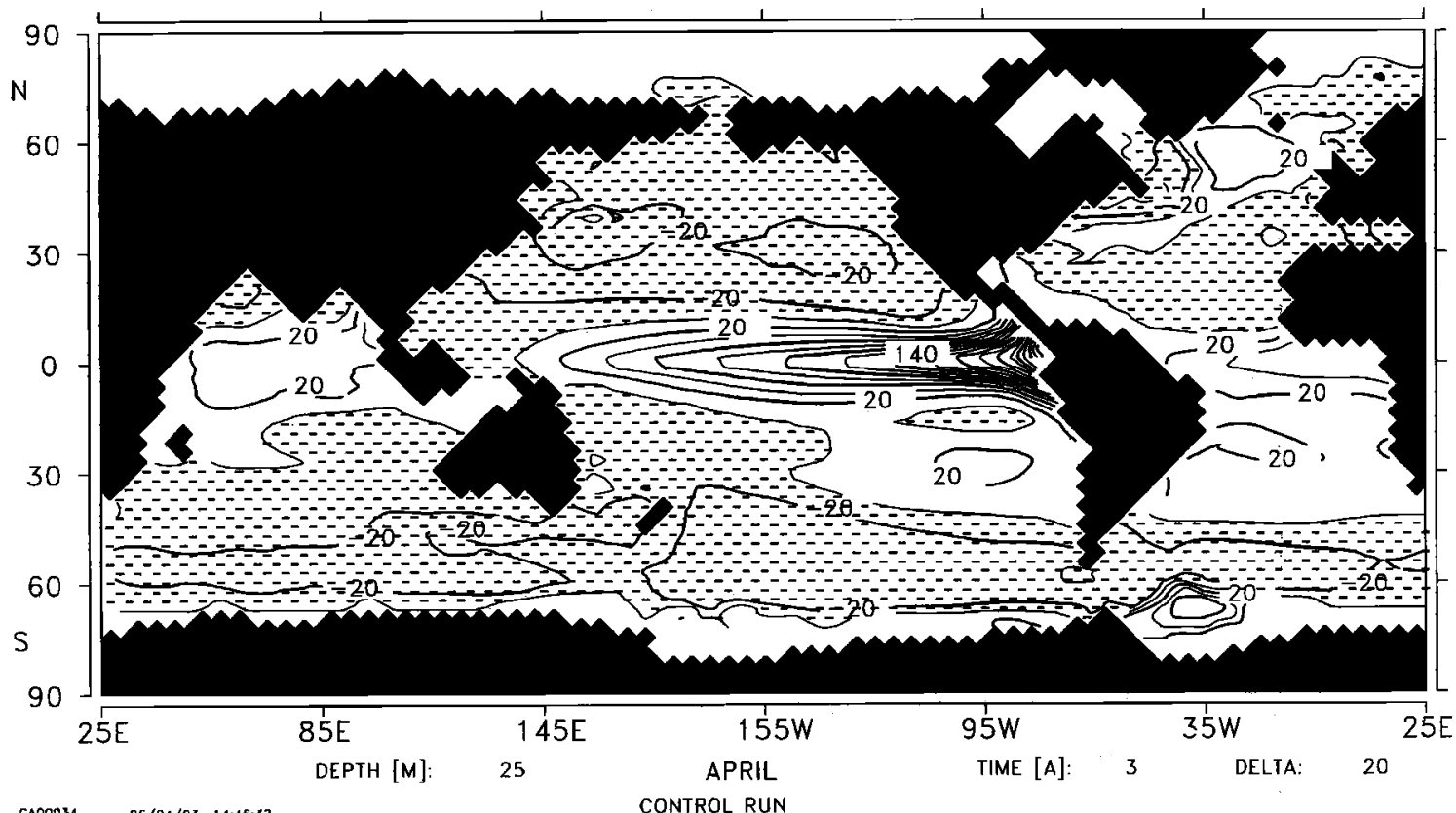

$\begin{array}{llll}{ }_{\text {CA00034 }} 06 / 04 / 93 & 14: 46: 32 & \text { CONTROL RUN }\end{array}$

b PHOSPHATE [(MOLES/LITER $) * 10 * *-6]$

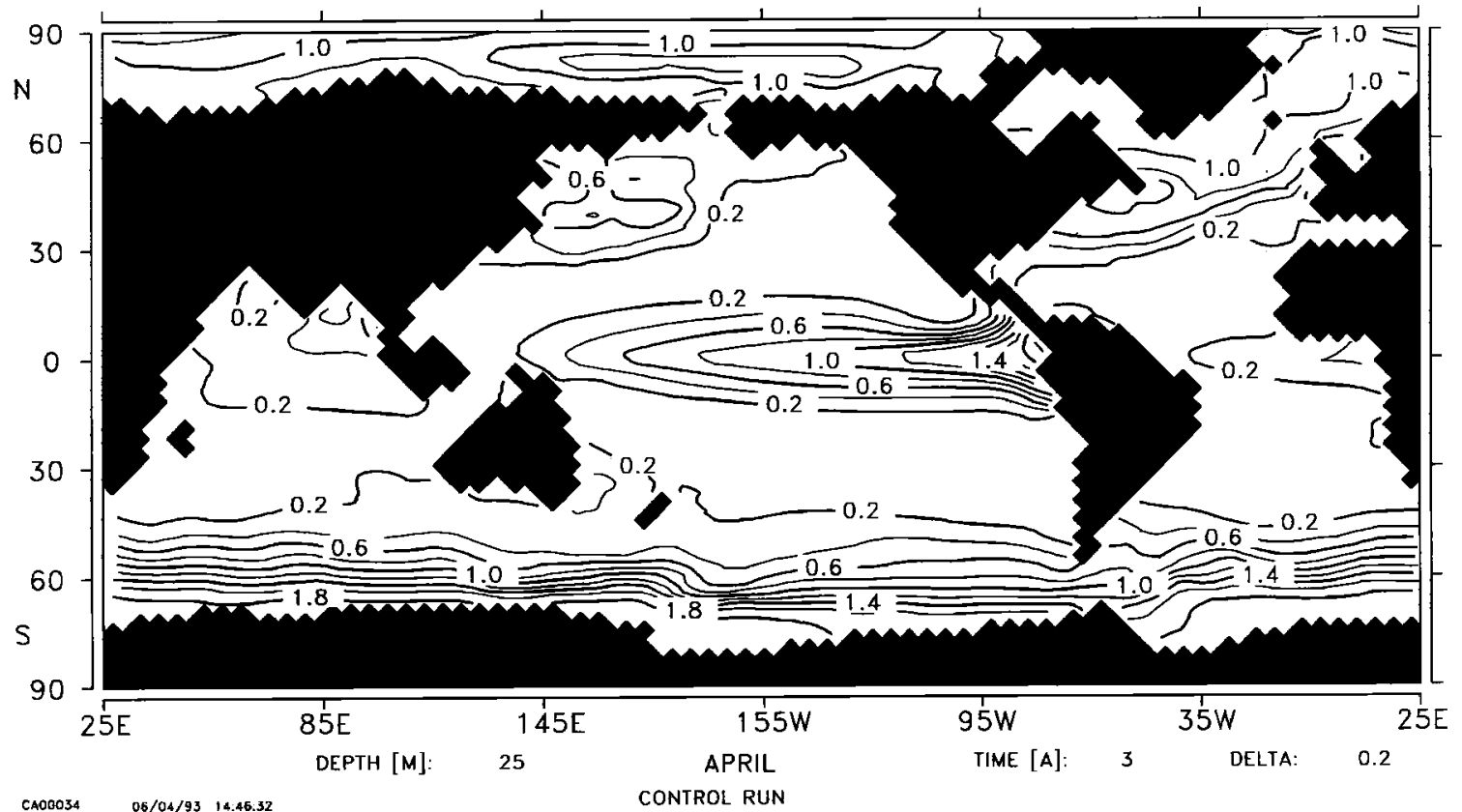

CA00034 $\quad 06 / 04 / 93 \quad 14.46 .32$

CONTROL RUN

Figure 5. Control run (oceanic surface layer), April: (a) $\Delta \mathrm{pCO}_{2}$ between ocean and atmosphere (contour interval $20 \mathrm{ppm}$ ), (b) phosphate (contour interval $0.2 \mu \mathrm{mol} \mathrm{L}^{-1}$ ), and (c) $\delta^{13} \mathrm{C}$ (contour interval $0.2 \%$ ). The differences in Figures $5 \mathrm{a}$ and $5 \mathrm{c}$ to the model version by Maier-Reimer et al. [1993] are due to the variable gas exchange coefficients. 
tations $\left(\delta^{13} \mathrm{C}\right.$ and $\left.\Delta^{14} \mathrm{C}\right)$. The model includes a diffusive atmosphere which has the same horizontal resolution as the ocean model. It assumes complete zonal mixing of the atmosphere within one month and an interhemispherical mixing of approximately one year. The inventories of phosphate, alkalinity, and $\mathrm{\Sigma CO}_{2}$ are adjusted to be in equilibrium (in the preindustrial state) with an atmospheric $\mathrm{pCO}_{2}$ of approximately $280 \mathrm{ppm}$.

For the unperturbed case the atmospheric isotope ratio $\delta^{13} \mathrm{C}$ is set to $-6.5 \%$ [Friedli et al., 1986]. The net gas exchange $F_{s a}$ from sea to air is given by the formula

$$
F_{s a}=k_{s a}\left(v_{10}, \vartheta, t\right)\left(P_{s}-P_{a}\right)
$$

where $P_{a}$ denotes the partial pressure of the gas in the atmosphere and $P_{s}$ the partial pressure of the sea surface. The gas exchange coefficient $k_{s a}$ is dependent on the surface wind speed $v_{10}$ in $10 \mathrm{~m}$ height, temperature $\vartheta$, and time $t$. In this study we choose spatially and seasonally variable gas exchange coefficients contrary to the constant value taken in the version of MaierReimer [1993]. The gas exchange coefficients are calculated with the Liss and Merlivat (LM) [1986] parameterization using the ECMWF analyses of wind stress and surface temperatures [Heimann and Monfray, 1991]. In the reference and experiment runs we use climatological monthly mean values of the gas exchange coefficient normalized to produce the global average $\mathrm{CO}_{2}$ flux of $0.06 \mathrm{~mol} \mathrm{~m}^{-2} \mathrm{ppm}^{-1} \mathrm{yr}^{-1}$ to match the Broecker et al. [1986] estimate from the uptake of bomb radiocarbon. The isotopic fractionation factors for the gas exchange are chosen as in the work by Maier-Reimer [1993].
The model computes the distribution of the oceanic tracers as a result of biogeochemical processes in the temporal evolution of the current field depending on the specified initial and lateral boundary conditions. The effects of fluctuations in the marine biota on the carbon cycle are taken into account. Export production, the part of primary production transported into deeper levels [Eppley and Peterson, 1979], is parametrized by the Michaelis Menten kinetic formula according to Dugdale [1967]. The formula depends on light intensity, phosphate, potential temperature $\vartheta$ and convective mixing. Phosphate, which is highly correlated in most parts of the ocean to nitrate, is chosen as limiting nutrient tracer. The rain ratio, defined as the ratio of soft tissue to hard calcareous shells [Broecker and Peng, 1982], is modeled as a function of temperature and the available amount of silicate [Maier-Reimer, 1993].

During photosynthesis ${ }^{12} \mathrm{C}$ is fixed in organic material with a slight preference over ${ }^{13} \mathrm{C}$. We use a constant ${ }^{13} \mathrm{C}$ fractionation. Fractionation of carbon isotopes in hard parts can be neglected [Degens et al., 1984].

Below the euphotic zone which is represented by the top 50-m-thick layer of the model, the downward flux of soft tissue is modeled proportional to $z^{-0.8}$, where $z$ denotes the depth according to Berger et al. [1987]. With increasing depth, concentrations of $\mathrm{\Sigma CO}_{2}$ and phosphate increase while $\mathrm{O}_{2}$ concentrations decrease through the remineralization of POC. The remineralization is limited to regions with sufficient oxygen. Unremineralized POC is preserved and advected by the current field. Exponential profiles are chosen for the fluxes of hard calcareous and opal shells. With a nearly

C

DELTA 13C

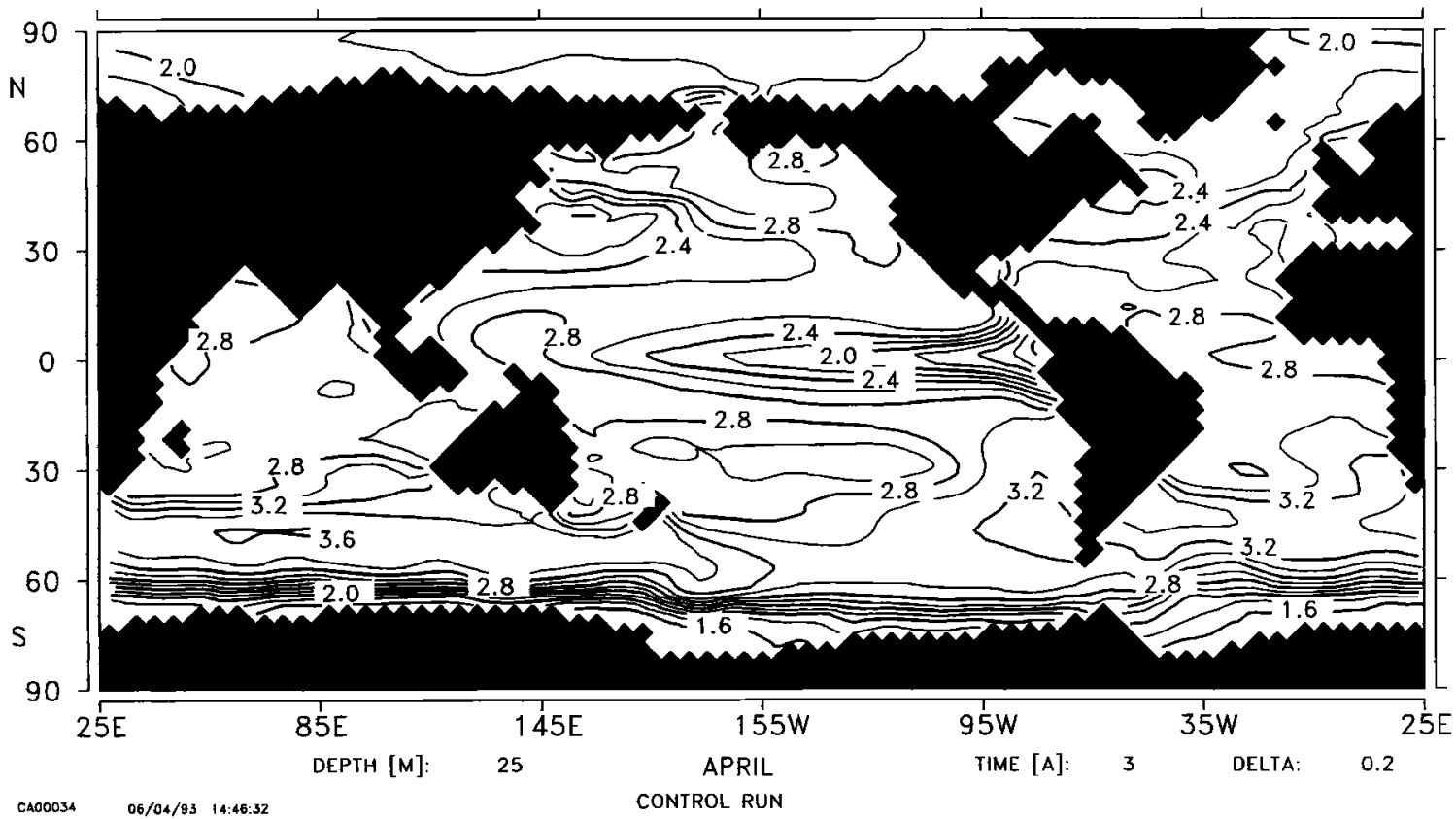

Fig. 5. (continued) 
constant $\mathrm{Ca}^{2+}$ concentration the dissolution of $\mathrm{CaCO}_{3}$ is only dependent on the concentration of carbonate ions.

\section{Control Run}

As a reference for the experiment run, a control run in the preindustrial state has been carried out. The boundary conditions for the reference state of the circulation model are the monthly climatological data sets of wind stress, air temperature, and sea surface salinity described in section 2. For comparison with the results of the sensitivity experiment (section 4) we display figures for the month of April, the month with the strongest modeled anomalies of geochemical tracers in the tropical Pacific during the El Niño event in $1982 / 1983$.

Figure $3 \mathrm{a}$ shows the horizontal velocity distribution of the uppermost model layer in the equatorial Pacific. The general features of the strong North and South Equatorial Currents are well reproduced in accordance with measurements during the Tahiti Shuttle Experiment [Wyrtki et al., 1981], but the Equatorial Counter Current cannot be simulated due to the coarse model resolution. Also, the Gulf Stream which has a extension of about $100 \mathrm{~km}$ [Dietrich et al., 1975] is underestimated in speed due to the coarse model resolution in this area (which is about $350 \mathrm{~km}$ ) and due to noneddy resolving model characteristics. The corresponding vertical velocity field (Figure $3 \mathrm{~b}$ ) is dominated by a too strong upwelling region in the equatorial tropics. Uncertainties in the data of the wind stress might be a reason for an overestimation of the upwelling since the vertical velocity essentially reflects curl $\tau / f$, where $\tau$ denotes the wind stress and $f$ the Coriolis parameter. Surface potential temperature is shown in Figure 4 with relatively cold water in the tropical eastern parts of the oceans due to upwelling.

The predicted distributions of the geochemical tracers reproduce the large-scale patterns of observed distributions, but not as well as the temperature and the salinity fields, to which the model is restored. Figure 5 a shows the difference of $\mathrm{pCO}_{2}$ between the ocean and the atmosphere for the stationary preindustrial value of $280 \mathrm{ppm}$ in the atmosphere. The $\Delta \mathrm{pCO}_{2}$ patterns are slightly different compared with the model results from Maier-Reimer [1993] due to different gas exchange coefficients and vertical resolutions of the models. In the tropics the model produces a big tongue of outgassing $\mathrm{CO}_{2}$ from the ocean. Cold carbon-rich water is upwelled near the coasts of western South America and Africa and causes a release of $\mathrm{CO}_{2}$ to the atmosphere. Main oceanic carbon sinks are cold surface waters of the high latitudes with high $\mathrm{CO}_{2}$ solubilities. In these regions, convective events perturb locally the surface $\mathrm{pCO}_{2}$ due to mixing with the underlying layers which have higher $\Sigma \mathrm{CO}_{2}$ concentrations than the surface.
Phosphate concentrations (Figure 5b) are maintained through the general circulation and export production. The model simulates export production depending on increasing light, temperature, nutrients, and stability conditions. The magnitude of this production is limited by the depletion of nutrients. High phosphate concentrations in the ACC are achieved by convective overturning and poor light concentrations [Kurz and MaierReimer, 1993]. In the tropics, with high temperatures and good light conditions, export production is only dependent on the nutrient concentrations. Together with upwelling of nutrients from deeper layers off the western coasts of the continents and their westward extension due to the equatorial current, the tropical eastern parts of the oceans are characterized as zones of high productivity. In the tropics the model locally reproduces a phosphate concentration approximately 1.5 times the values observed by J. Reid [Kurz and Maier-Reimer, 1993]. This might be a result of cumulative strong upwelling at the equator and oversimplification of the biological processes.

The distribution of $\delta^{13} \mathrm{C}$ (Figure $5 \mathrm{c}$ ) is mainly determined by productivity but also by temperature directly [Mook et al., 1974] and by the strength of the gas exchange [Broecker and Maier-Reimer, 1992]. In tropical and subtropical regions, warm waters lower $\delta^{13} \mathrm{C}$ values due to thermodynamic effects related to air-sea $\mathrm{CO}_{2}$ exchange. An opposing effect is the preference of ${ }^{12} \mathrm{C}$ during the formation of soft tissue. This effect causes high $\delta^{13} \mathrm{C}$ values in areas of high productivity (e.g., the equatorial upwelling area). On a global scale, surface $\delta^{13} \mathrm{C}$ values are determined by the horizontal temperature gradient, and reduced by half by the marine biology.

The tracer distributions of the present 11-layer model and the 15-layer version of Maier-Reimer [1993] generally have the same features. In the 11-layer version, in which higher numerical diffusivity reduces vertical gradients, the deep waters exhibit younger ${ }^{14} \mathrm{C}$ ages than the 15-layer version. The global patterns of the ${ }^{14} \mathrm{C}$ distribution from the 15-layer HAMOCC-3 model are well reproduced in accordance with the GEOSECS sections [Bainbridge, 1975, 1976]. A pronounced discrepancy between both model versions and the observations is found in the northern North Pacific, where the models predict a too strong stability of the stratification.

\section{Experiment}

In the experiment the on-line coupled Hamburg LSG and carbon cycle models were forced with surface wind stress and air temperature anomalies derived from a ECMWF data set. This data set was compiled from $12-$ hour ECMWF analyses estimated by data assimilation of observations from stations, ships, and buoys into the ECMWF-numerical weather prediction model [Bengtsson et al., 1982; Shaw et al., 1987]. The ECMWF 
data with a $2.5^{\circ}$-grid resolution were transformed into anomalies by monthly averaging and subtracting the monthly mean over the period from 1981 to 1987 from each individual month [Segschneider, 1991]. The monthly anomalies of surface air temperature and wind stress were interpolated to the model grid and added to the corresponding climatologies used in the control run (see section 3). For $\mathrm{CO}_{2}$ gas exchange the same climatological monthly LM parametrized coefficients were used as in the control run (see section 2). The experiment was started from a preindustrial stationary state of the carbon cycle model. No anthropogenic $\mathrm{CO}_{2}$ emissions were included in the simulation.

The model results of the experiment for the $\mathrm{El}$ Niño in April 1983 are shown in Figures 6-8. Figure 6a shows horizontal velocities in the surface layer with a large reduction in the eastern side of the equatorial Pacific due to a weak Walker circulation in the atmosphere. The equatorial current is much slower, by more than 20 $\mathrm{cm} \mathrm{s}^{-1}$ than in the control run (Figure $3 \mathrm{a}$ ). The Peru-

8

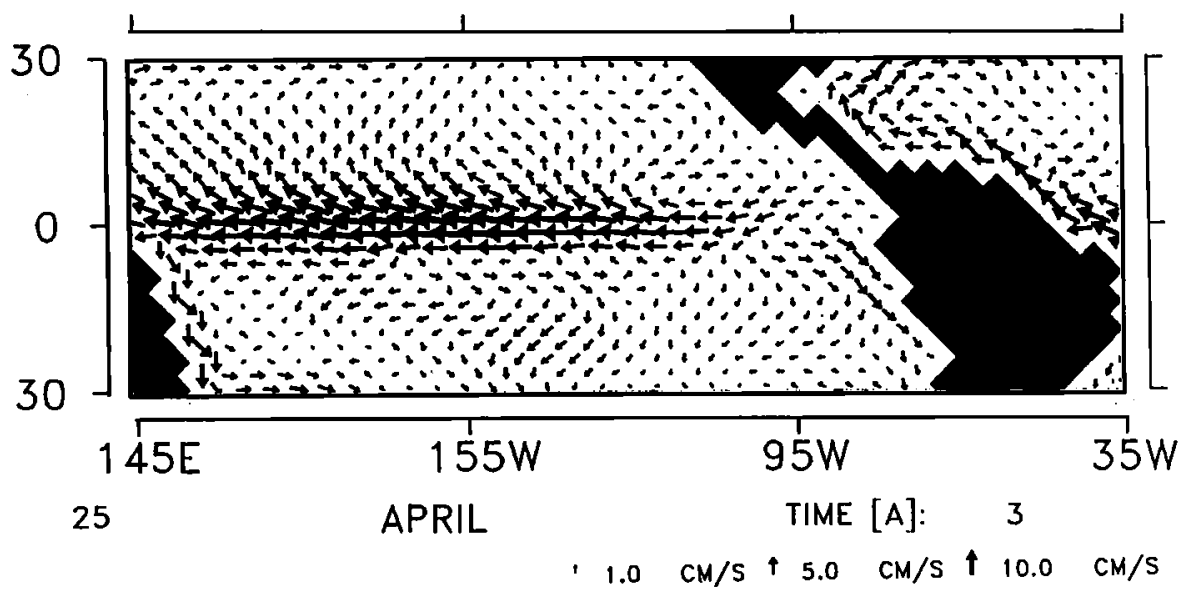

b

VERTICAL VELOCITY $\left[10^{* *-6} \mathrm{M} / \mathrm{S}\right]$

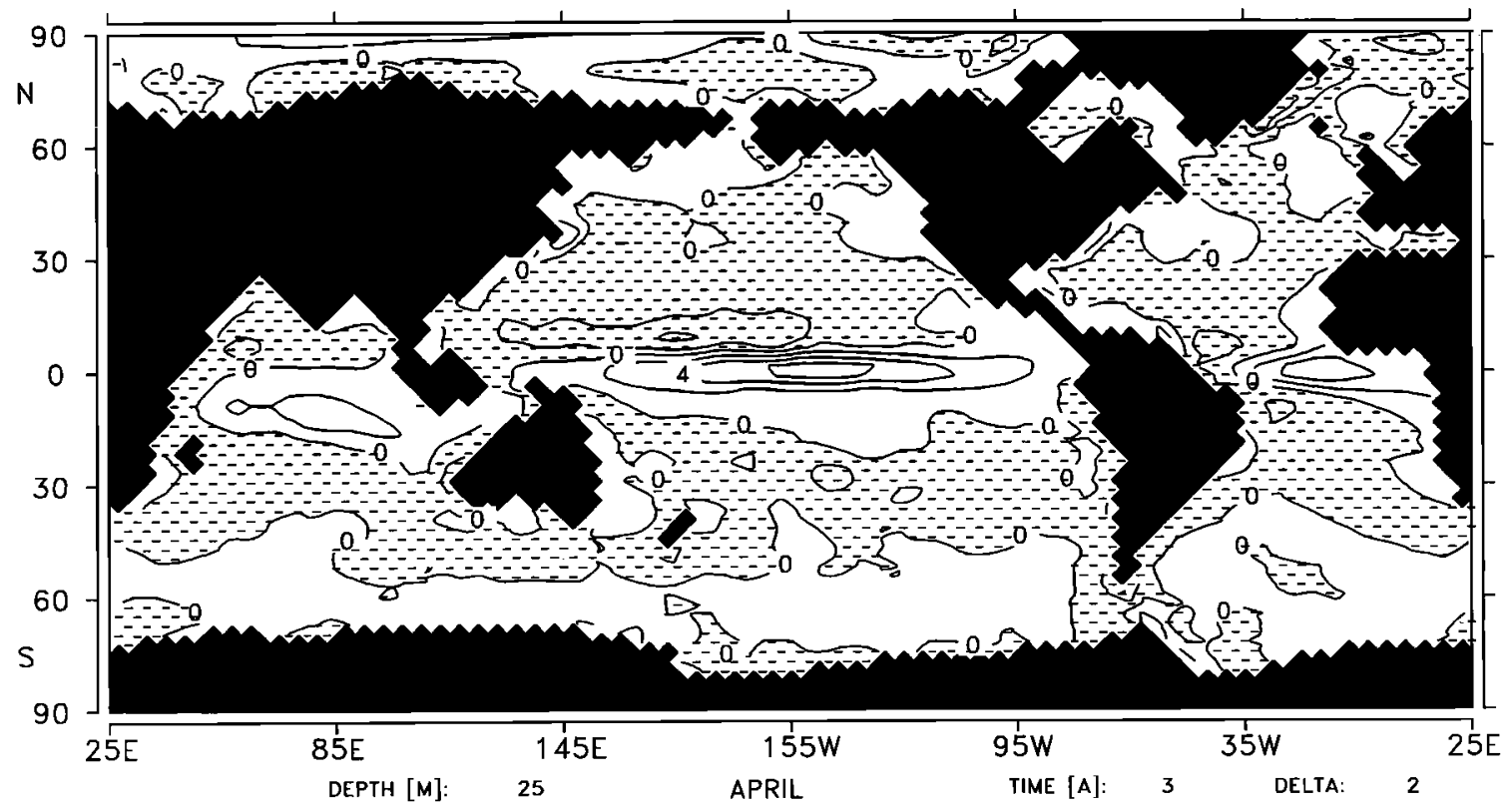

$\begin{array}{lllll}K_{\mathrm{POO}} & 06 / 04 / 93 & 16: 57: 39 & \text { ECMWF RUN }\end{array}$

Figure 6. Experiment, April 1983: (a) horizontal velocity in oceanic surface layer of the equatorial Pacific and (b) vertical velocity (between surface and second layer, contour interval $2 \times 10^{-6}$ $\left.\mathrm{m} \mathrm{s}^{-1}\right)$. 


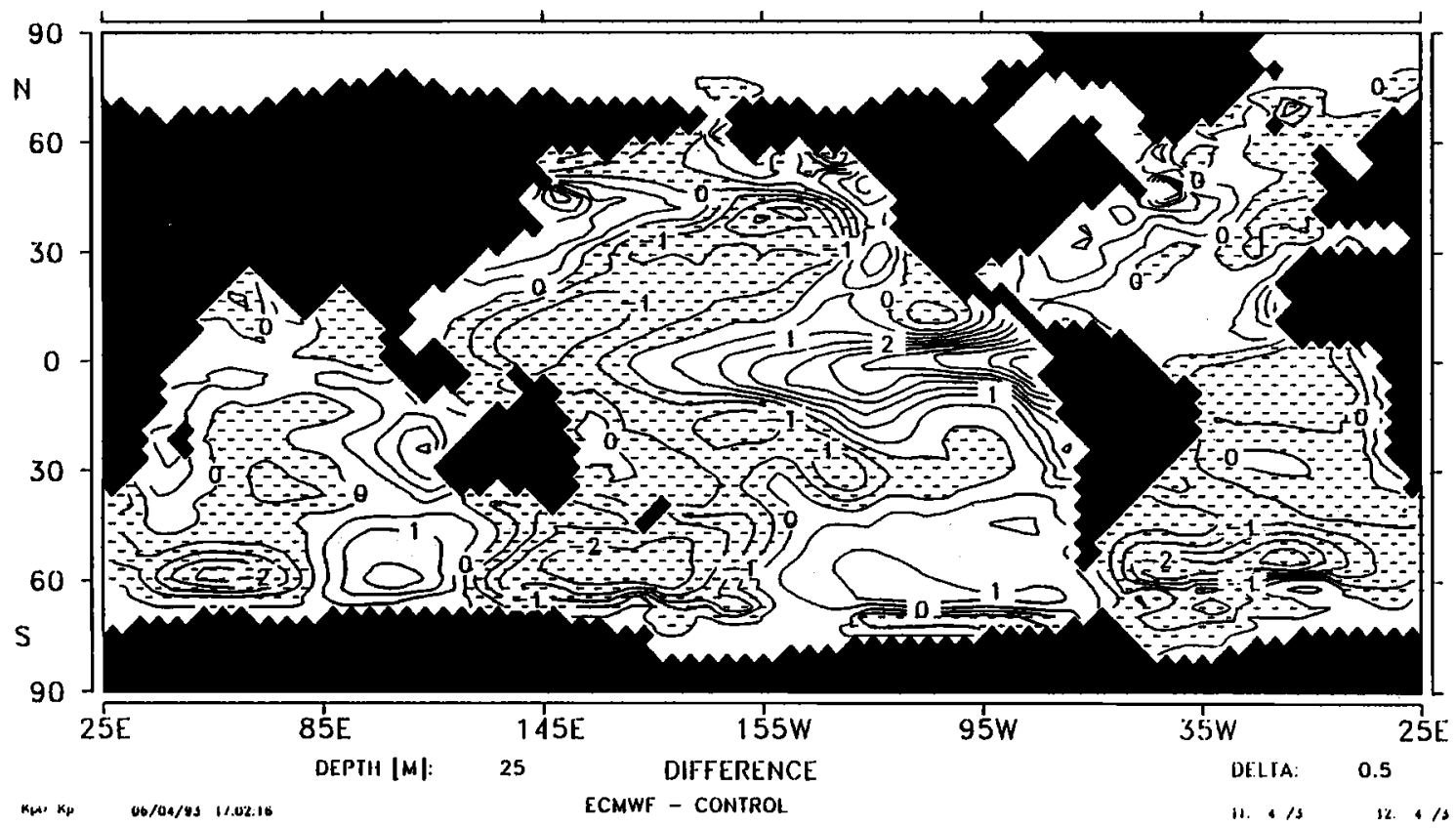

b Observed Pot. Temperature [ ${ }^{\circ} \mathrm{C}$ ]

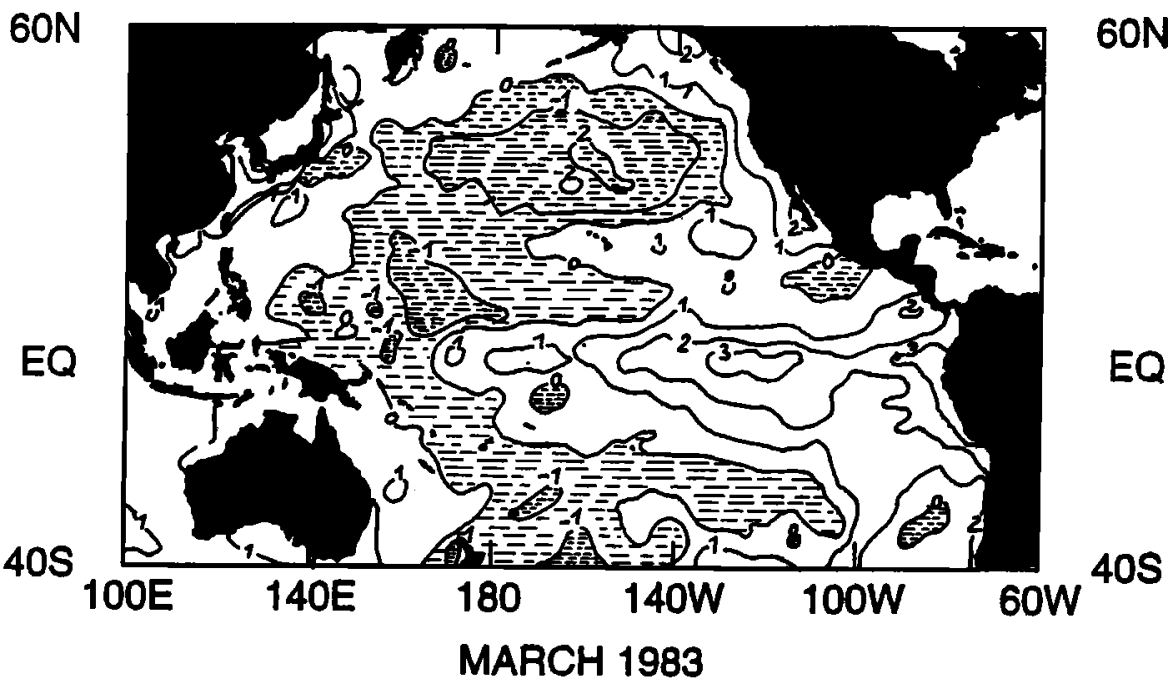

Figure 7. Sea surface temperature (SST) anomalies during El Niño 1982/1983: (a) difference. of experiment and control run in April 1983 and (b) observed SST for the Pacific in March 1983 after Rasmusson and Hall [1983] (contour interval $1^{\circ} \mathrm{C}$ ).

vian Current changes its direction and flows southwards along the South American coast. In the Indian Ocean a weak winter monsoon causes a westward directed North Equatorial Current. Unlike in the Pacific the equatorial current in the Atlantic is strengthened in its western part.

The upwelling velocity of the experiment is shown for April 1983 in Figure 6b. A comparison with the control run (Figure $3 \mathrm{~b}$ ) indicates a significant decrease of the upwelling in the central and eastern Pacific. Maximal changes are found off the coast of Peru where the upwelling almost vanishes (i.e., a reduction of more than 6 $\mathrm{x} 10^{-6} \mathrm{~m} \mathrm{~s}^{-1}$ ), and in the central Pacific with a reduction from $10^{-5} \mathrm{~m} \mathrm{~s}^{-1}$ to $6 \times 10^{-6} \mathrm{~m} \mathrm{~s}^{-1}$. The downwelling area north of the equator is shifted westward and has gained in strength, while south of the equa- 
tor the downwelling area has decreased. The changes in the Atlantic are much smaller than the variations in the Pacific and are not further discussed here.

Reynolds et al. [1989] found that the variations in the assimilated ECMWF wind fields seem to be too weak in comparison with buoy data of the Pacific Marine Enviromental Laboratory (PMEL) in the tropics. Comparison of the daily ECMWF wind speeds with those from the U.S. National Meteorological Center shows root mean square differences up to $5 \mathrm{~m} \mathrm{~s}^{-1}$ in the high latitudes. This can lead to errors in the daily wind stress data up to $25 \%$ [Trenberth et al., 1989]. Thus the simulated fluctuations of the equatorial upwelling might be underestimated. In higher latitudes, especially in the Southern Ocean and in the northern North Atlantic, HAMOCC-3 model results are dependent on the sparse database. Model runs including freshwater anomalies, which are not globally available for the period between 1981 and 1987, would possibly improve predictions in this regions compared to the present version with prescribed sea surface salinity. Strong anomalies of high-latitude wind speed and air temperatures partly induce unrealistic convective overturning. This is an effect of spinning-up the model with climatological boundary values which contains no variability. In tropical regions with linear response characteristics this does not make much difference whereas in high latitudes, where the response is essentially dominated by the nonlinear effects of convection and sea ice, the sud- den introduction of variability tends to generate a considerable model drift. Convective overturning causes a mixing of tracers from deeper layers to the surface and can hence disturb the global signal. However, a large reduction of equatorial upwelling during the ENSO period and enforced upward vertical velocity into the uppermost tropical layer during La Niña events are produced by the model simulations. El Niño episodes are separated by La Niña periods when oceanic and atmospheric conditions are complementary to those during El Niño. During La Niña episodes the Southern Oscillation index is unusually high combined with anomalously cooler equatorial Pacific sea surface temperatures and very intensive trade winds [Philander, 1990].

The differences in sea surface temperature between the experiment and control run are shown in Figure 7a. The general features of the anomalies in the Pacific are in good agreement with the observations (Figure 7b) from Rasmusson and Hall [1983]. A large tongue of anomalously warm water reaching from the coast of Peru and California to the central tropical Pacific replaces the cold water of the upwelling areas along the western coasts of America. An extreme positive anomaly in the SST with more than $3^{\circ} \mathrm{C}$ is simulated by the model in agreement with observations. The negative anomaly in the North Pacific of up to $2^{\circ} \mathrm{C}$ is reproduced by the model too, but underestimated by about $0.5^{\circ} \mathrm{C}$. In the South Pacific the negative values predicted by the model agree with the observations. The negative

a

OCEAN-ATMOSPHERE DIFFERENCE IN PCO2

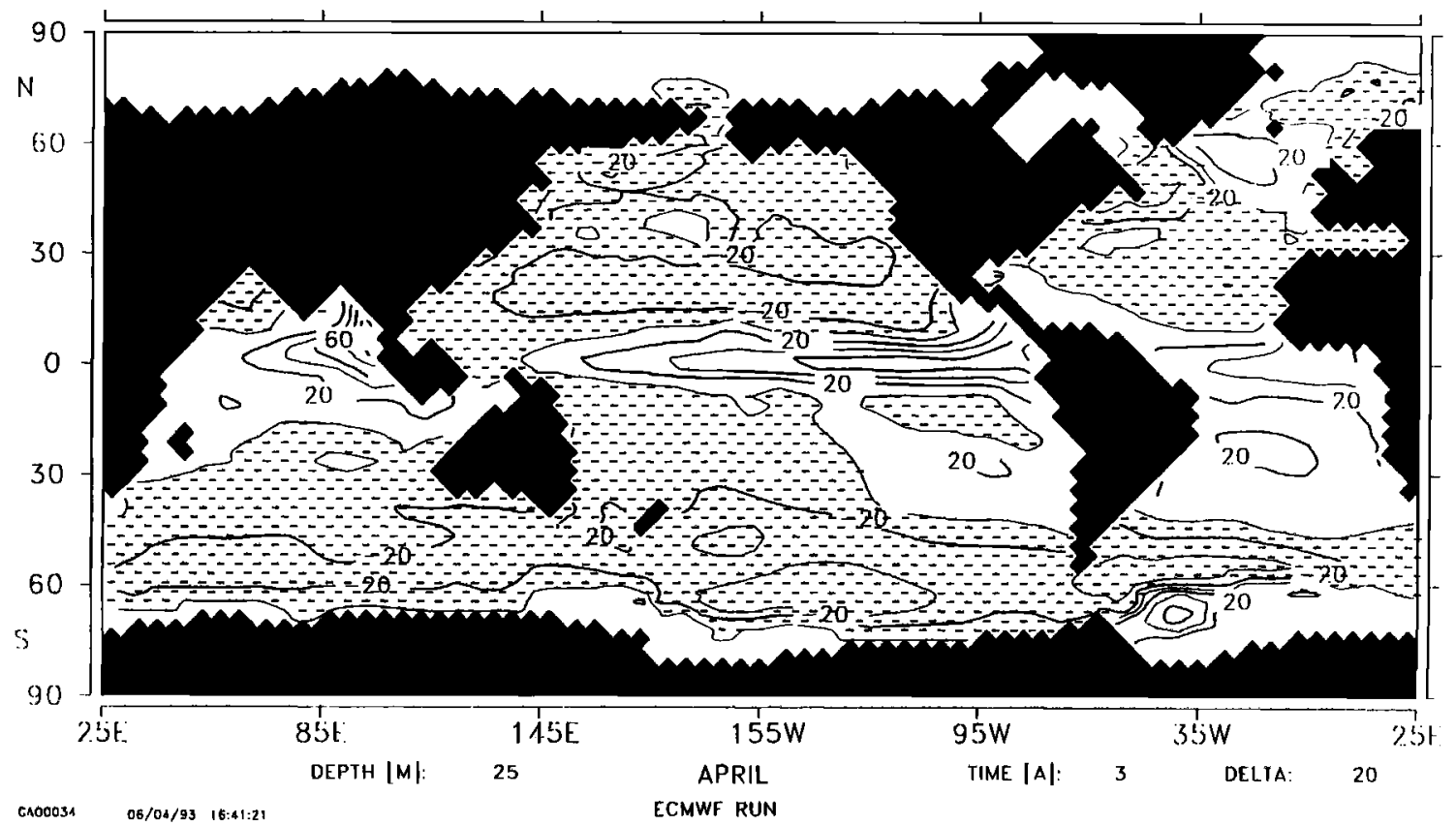

Figure 8. Experiment (oceanic surface layer), April 1983: (a) $\Delta \mathrm{pCO}_{2}$ between ocean and atmosphere (contour interval $20 \mathrm{ppm}$ ), (b) phosphate (contour interval $0.2 \mu \mathrm{mol} \mathrm{L} \mathrm{L}^{-1}$ ), and (c) $\delta^{13} \mathrm{C}$ (contour interval: $0.2 \%$ ). 
anomalies of the South Atlantic, in contrast to those in the Indian, are not correlated to the ENSO [Pan and Oort, 1990].

Figure 8a shows the difference in $\mathrm{pCO}_{2}$ between ocean and atmosphere for April 1983. The equatorial high of oceanic $\mathrm{pCO}_{2}$ in the eastern Pacific is decreased by more than $100 \mathrm{ppm}$ relative to the control run (Figure 5a) due to reduced upwelling of carbon rich water. The large warming in the equatorial Pacific, which causes a lower solubility and hence stronger outgassing of $\mathrm{CO}_{2}$, compensates for about $40 \%$ the upwelling effects [Volk, 1989]. Also, a reduced biological production would have an effect contrary to that of the change in the circulation (see section 1). In the eastern Indian Ocean the

b

PHOSPHATE $[($ MOLES/LITER $) * 10 * *-6]$

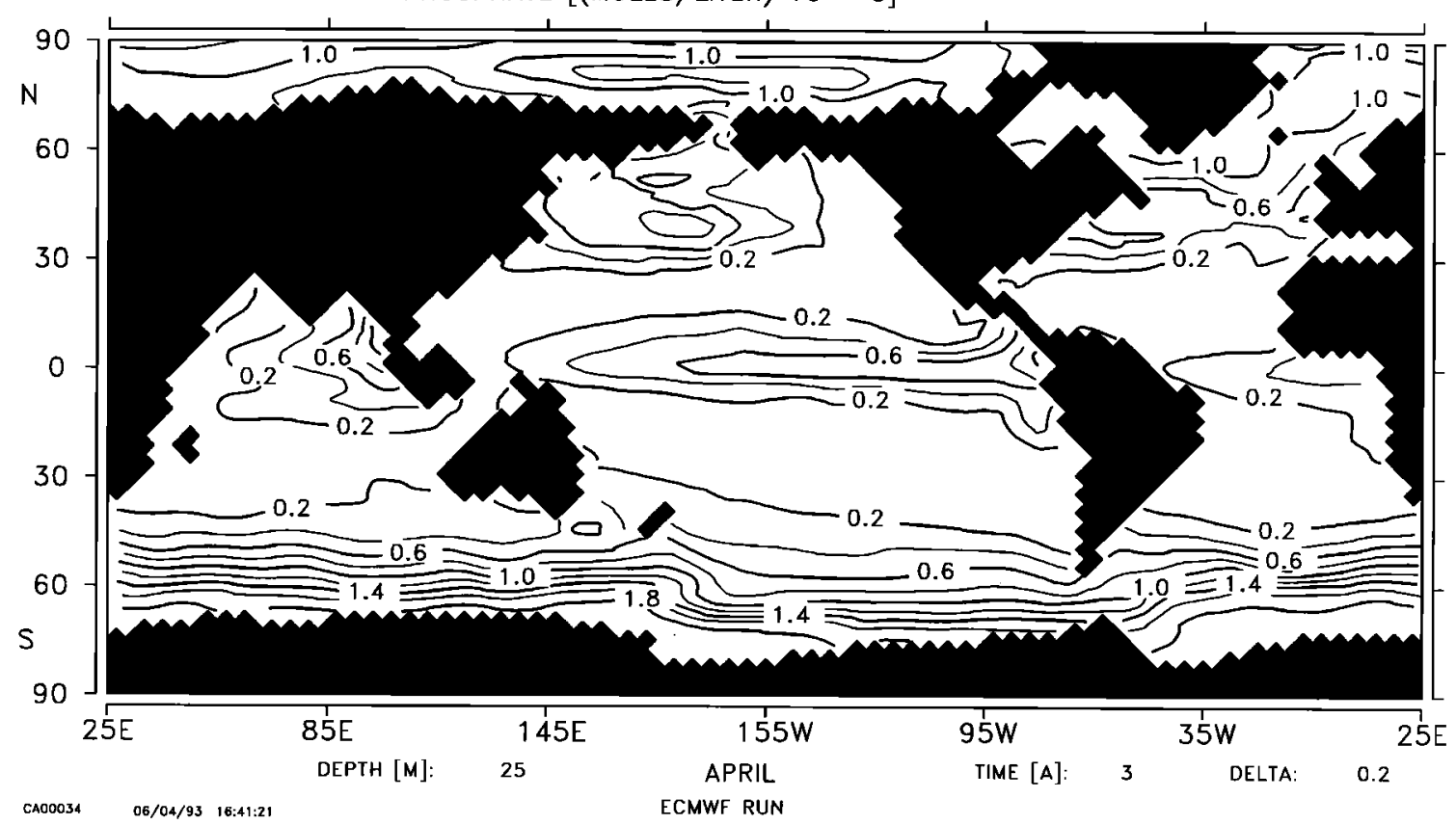

C DELTA $13 \mathrm{C}$

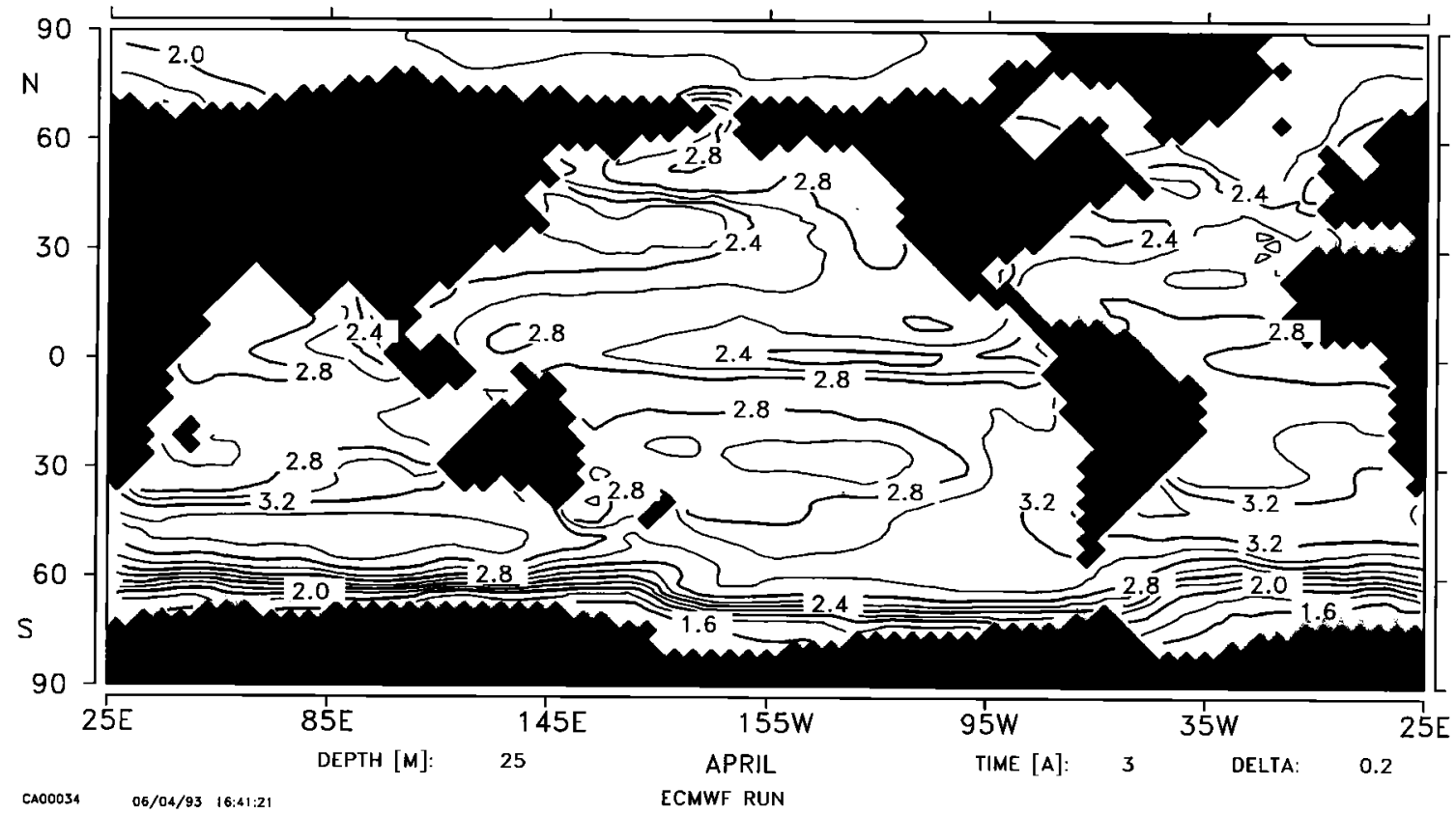

Fig. 8. (continued) 
model predicts a decrease of $\mathrm{pCO}_{2}$ from the reduced upwelling similarly to the eastern Pacific, while variations in the high latitudes $\Delta \mathrm{pCO}_{2}$ values do not differ significantly from the control run.

Figure $8 \mathrm{~b}$ shows the predicted phosphate concentration in the experiment. The local maximum of more than $0.6 \mu \mathrm{mol} \mathrm{L}{ }^{-1}$, which is seen off the Peruvian coast, is significant lower than the maximum of the control run in Figure $5 \mathrm{~b}$ by more than $1 \mu \mathrm{mol} \mathrm{L} \mathrm{L}^{-1}$. With reduced upwelling the supply of nutrients from deeper layers decreases. As a consequence, the remaining phosphate in the mixed layer is consumed by export production. The export production in the tropics is mainly determined by nutrient concentration and decreases in the eastern equatorial Pacific by $50 \%$ as a consequence of the phosphate reduction.

The changes of the isotopic ratio of dissolved inorganic carbon (the experiment run is shown in Figure $8 c$ ) are caused by changes in the circulation, temperature and export production. The general features of the anomalies, as compared to the control run, are inverse to those of the phosphate concentration. In the Eastern Pacific we find a maximum increase up to $0.6 \%$. Increasing temperature and a reduction in export production would lead to a decrease of $\delta^{13} \mathrm{C}$, but less upwelling of deep water with low $\delta^{13} \mathrm{C}$ values causes an increase of the ratio.

Figure 9 shows time latitude diagrams for zonal mean differences over the Pacific basin from 1981 to 1987 between experiment and control run. Negative anomalies of the vertical velocity (Figure 9a) in the equatorial area can be found from August 1982 to late 1983, with lowest values in January 1983 of less than $2 \times 10^{-6} \mathrm{~m} \mathrm{~s}^{-1}$. In April 1984 a very strong La Niña month, a maximum of upwelling occurs with an anomaly about half of the magnitude of the El Niño of 1983. A second maximum is predicted two years later with an anomaly of approximately $2 \times 10^{-6} \mathrm{~m} \mathrm{~s}^{-1}$. In the following weak $1986 / 1988$ El Niño the Ekman induced upwelling is only slightly reduced due to a weak representation of the event in the ECMWF wind data. Consistently to the reduced upwelling during the El Niño 1982/1983 a strong posi-

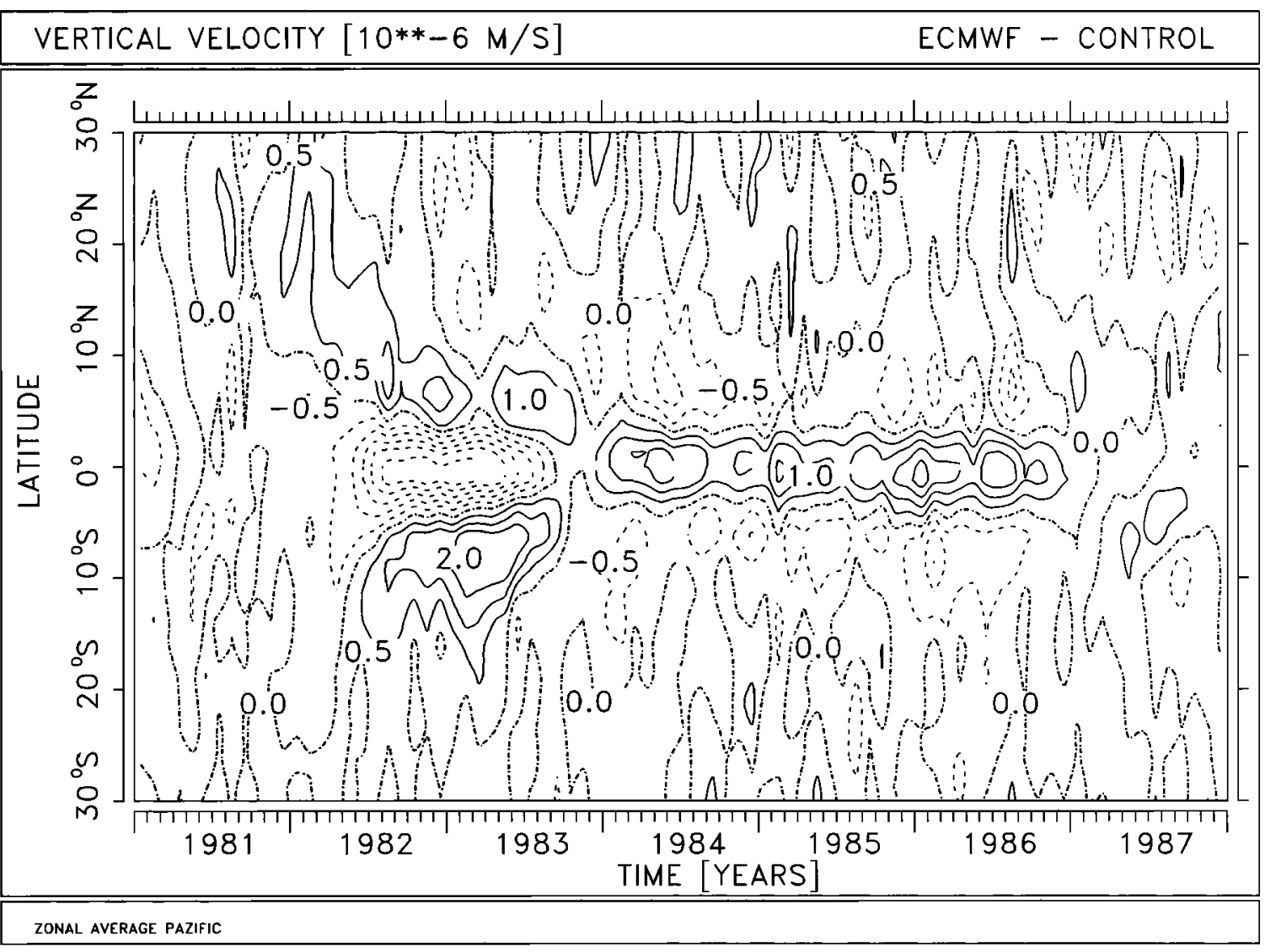

Figure 9. Time-latitude evolutions of zonal mean differences between experiment and control run in the Pacific surface layer: (a) vertical velocity (between surface and second layer, contour interval $0.5 \times 10^{-6} \mathrm{~m} \mathrm{~s}^{-1}$ ), (b) sea surface temperature (SST) (contour interval $0.25^{\circ} \mathrm{C}$ ), (c) $\Delta$ $\mathrm{pCO}_{2}$ between ocean and atmosphere (contour interval $5 \mathrm{ppm}$ ), (d) phosphate (contour interval $0.05 \mu \mathrm{mol} \mathrm{L}{ }^{-1}$ ), (e) export production (contour interval $0.5 \mathrm{~g} \mathrm{~m}^{-2}$ month $^{-1}$ ), and (f) $\delta^{13} \mathrm{C}$ (contour interval $0.05 \%$ ). 


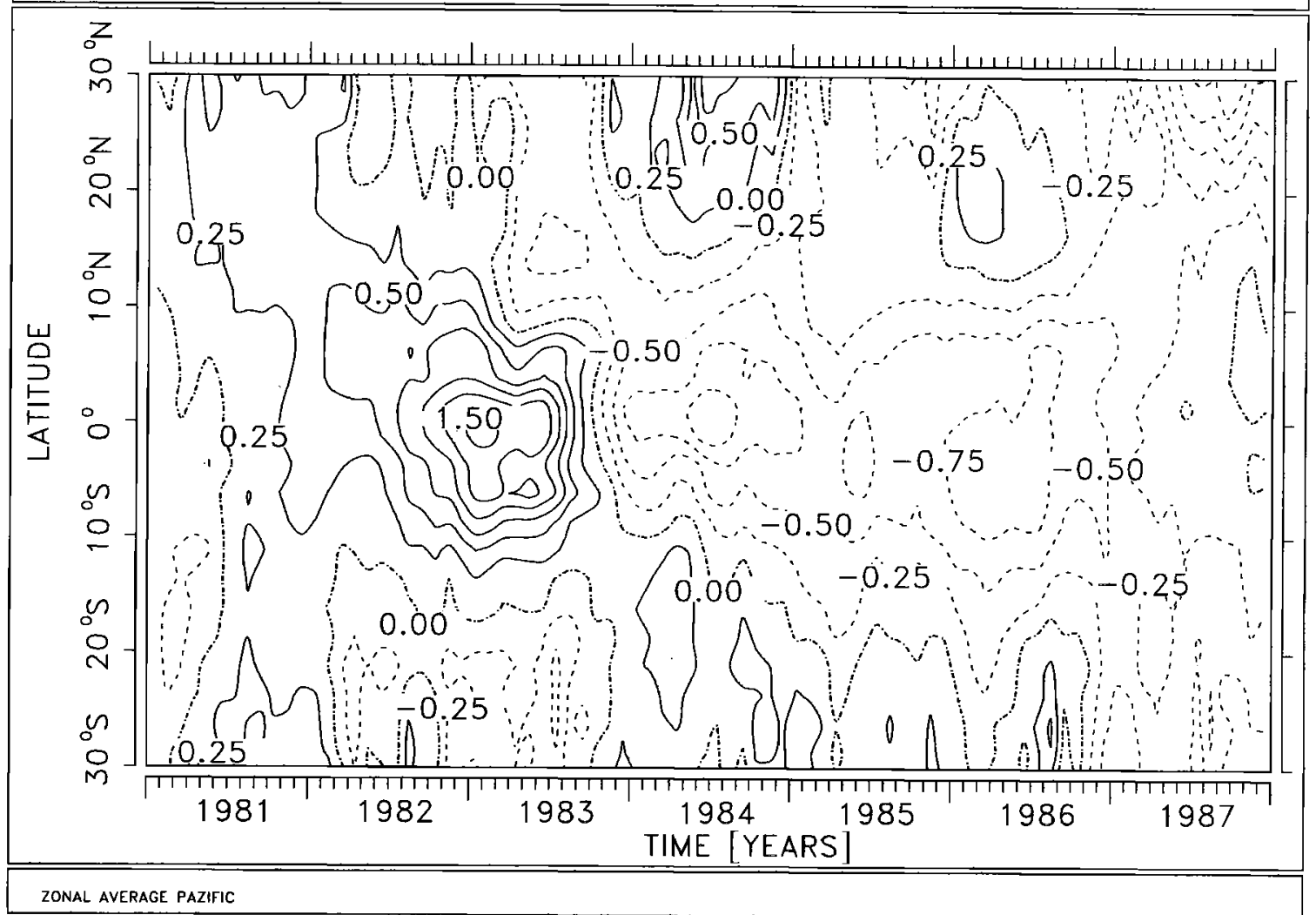

c

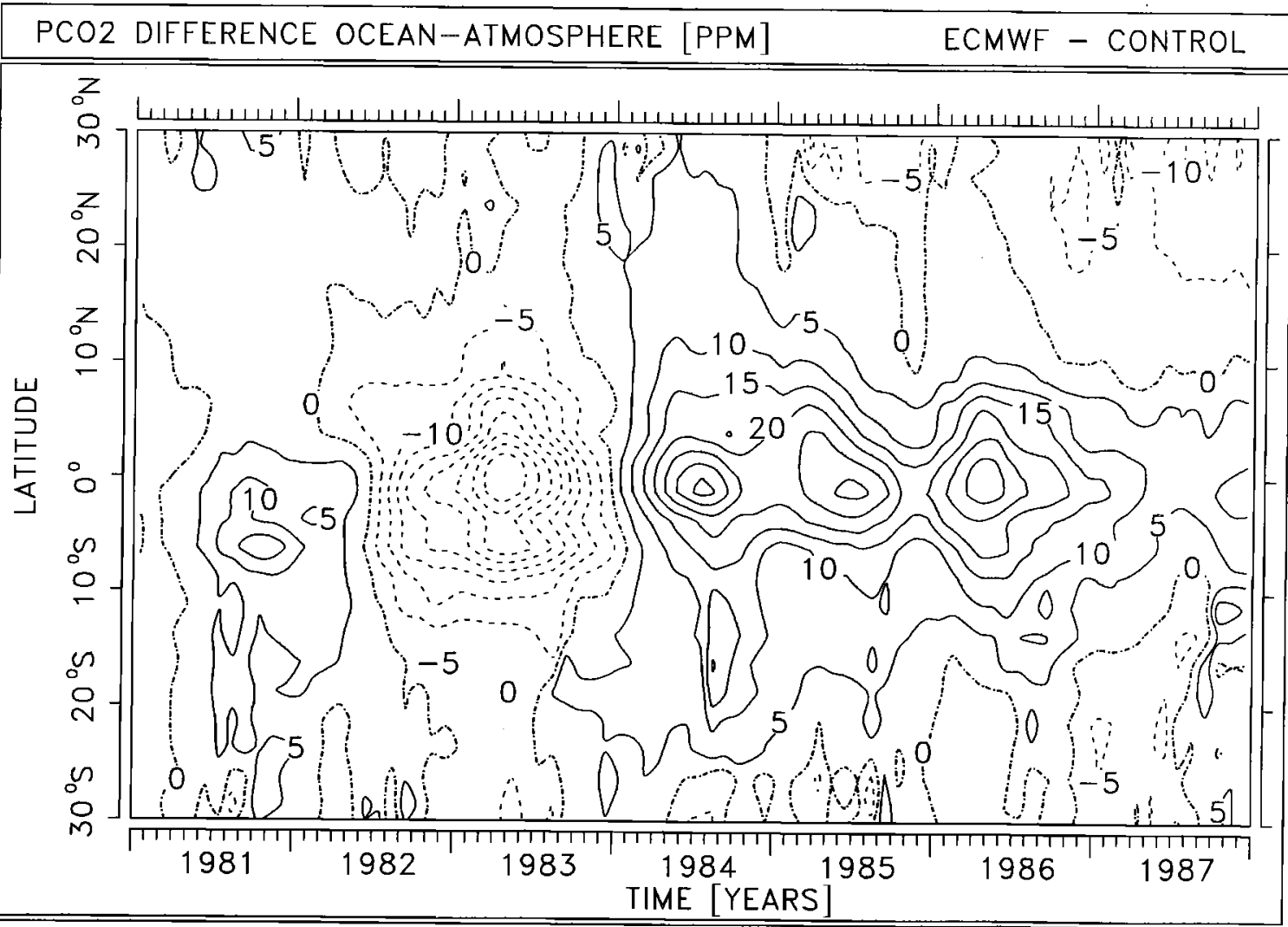


\begin{tabular}{|ll}
\hline PHOSPHATE $[($ MOLES/LITER $) * 10 * *-6]$ & ECMWF - CONTROL
\end{tabular}

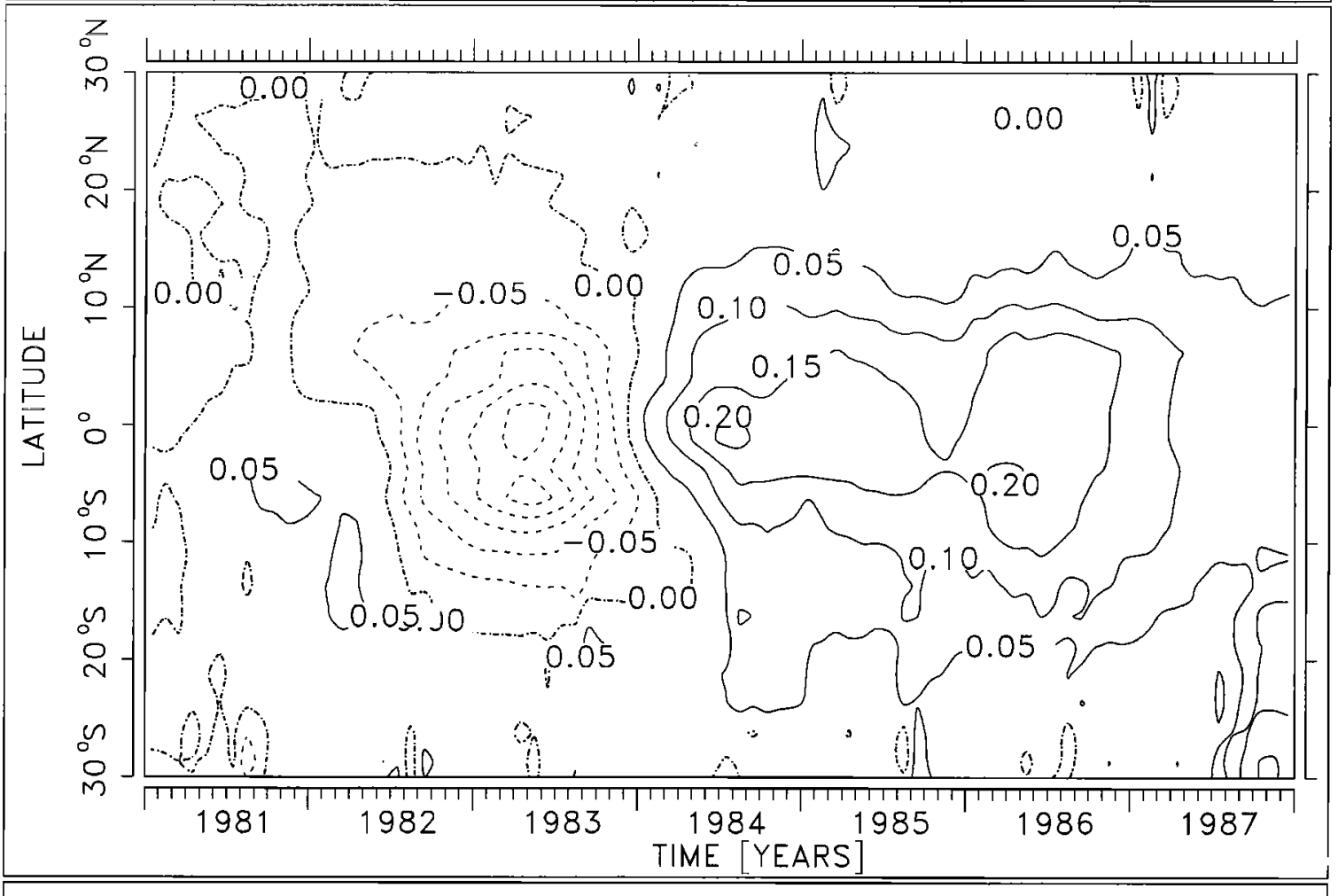

ZONAL AVERAGE PAZIFIC

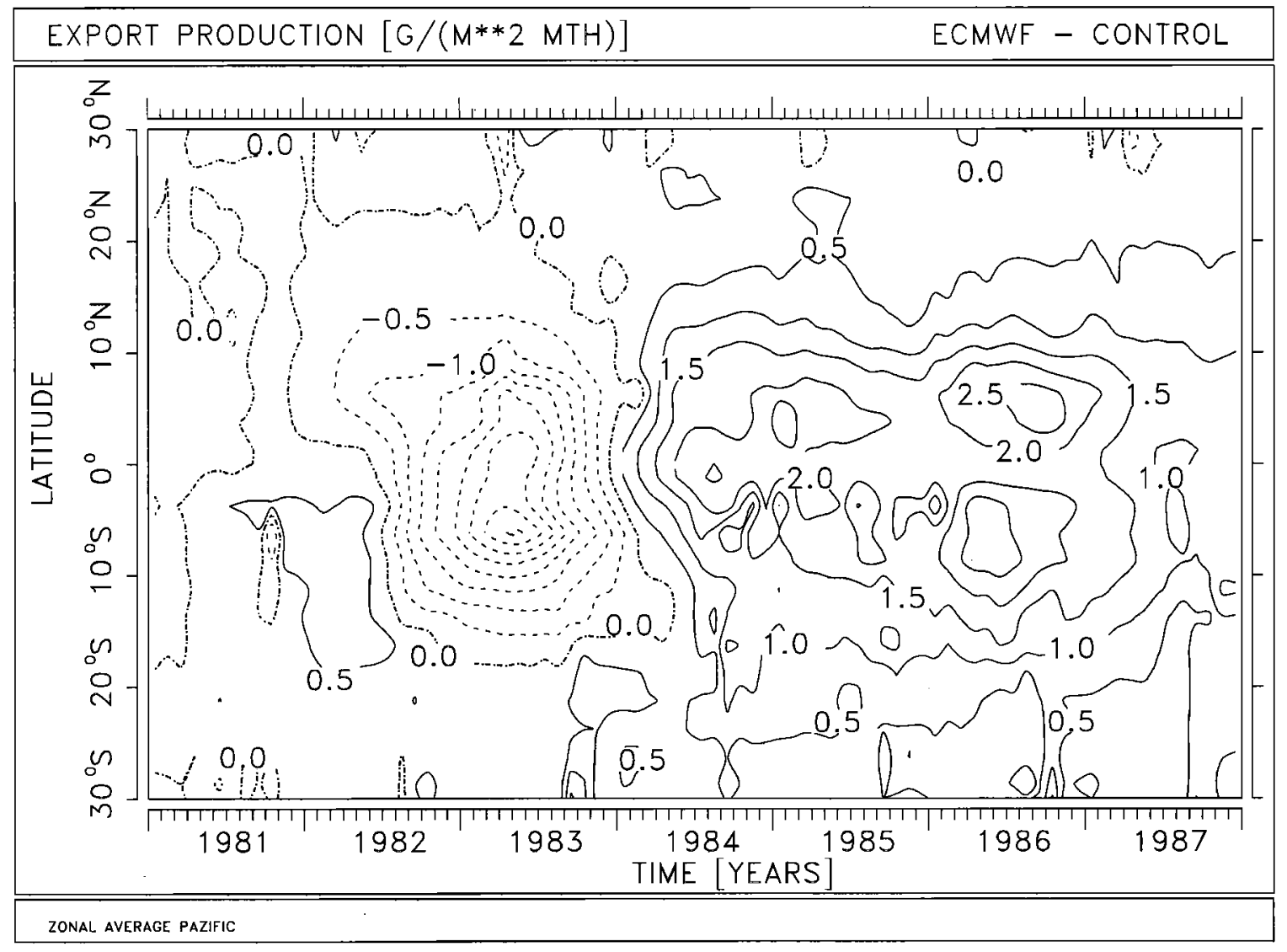

Fig. 9. (continued) 


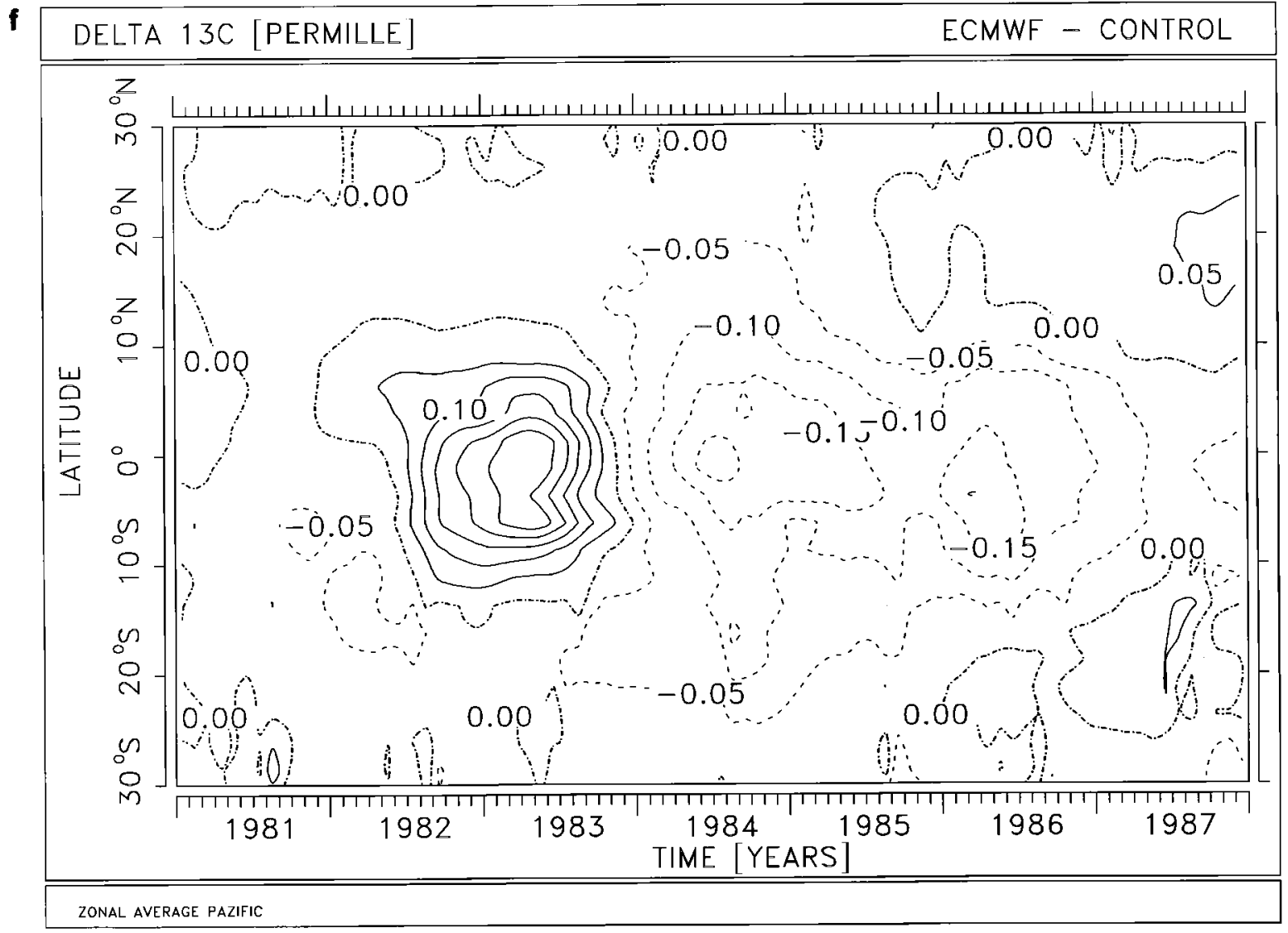

Fig. 9. (continued)

tive temperature anomaly extending from $10^{\circ} \mathrm{N}$ to $10^{\circ} \mathrm{S}$ (Figure $9 \mathrm{~b}$ ) with a zonally averaged maximum of over $1.5^{\circ} \mathrm{C}$ can be recognized between January and July in 1983. Negative anomalies (relative to the control run) start in the beginning of 1984 and reach their minimum in fall 1984. A cold phase, showing reduced temperatures by more than $1^{\circ} \mathrm{C}$, can be observed through 1986 with relative warming beginning in the second half of the year. The simulations show an increase in temperature during the weak El Niño 1986/1988, but the warming predicted by the model has only half of the magnitude as the observations reported by Reynolds [1988]. An explanation for this difference between model results and observations can be the short period of 7 years to construct the ECMWF mean values including one strong and one weak El Niño event, and only one strong La Niña event. Hence positive anomalies are expected to be too weak and negative anomalies to be too strong.

The zonally averaged anomalies of computed $\mathrm{CO}_{2}$ partial pressure between ocean and atmosphere (Figure $9 \mathrm{c}$ ) decrease by more than $40 \mathrm{ppm}$ in the El Niño $1982 / 1983$. The maximum of change in $\Delta \mathrm{pCO}_{2}$ is lagged by about 3 months between the minimum of the Southern Oscillation index and is similar to calculations with box models [Volk, 1989]. The $40 \mathrm{ppm}$ decline predicted by the model is smaller than the observed 55 ppm decline toward a vanishing $\Delta \mathrm{pCO}_{2}$ gradient between the tropical ocean and atmosphere [Keeling and Revelle, 1985,Feely et al., 1987]. The difference might be caused by the overestimated tropical upwelling in the model (see section 3 ). Considering that warming of the surface layer and a decline in the export production would lead to an increase of oceanic $\mathrm{pCO}_{2}$, a reduction of the partial pressure can only be explained by less vertical upwelling bringing less dissolved inorganic carbon to the surface. With the onset of trade winds the $\mathrm{pCO}_{2}$ minimum vanishes in late 1983. In the following summer, when La Niña reaches its maximum, an excess of over $30 \mathrm{ppm}$ above the climatological mean is simulated. After a second maximum 2 years later the anomaly decreases again with the beginning of the $\mathrm{El}$ Niño 1986/1988. This tendency is in agreement with observations from Wong et al. [1993].

The phosphate concentration (Figure 9d) reaches a minimum in April 1983 with a time lag of approximately 3 months to the upwelling anomalies. In spite of increasing temperature, export production (Figure $9 \mathrm{e})$ declines with the decrease of phosphate. The max- 
imum change of export production occurring around April 1983 was $-4.5 \mathrm{gC} \mathrm{m}^{-2}$ month $^{-1}$. These results confirm the box model studies from Volk [1989] with a maximum shift between -2.2 to $-3.5 \mathrm{~mol} \mathrm{C} \mathrm{m}^{-2} \mathrm{yr}^{-1}$ (人) $\mathrm{gC} \mathrm{m}^{-2}$ month $\left.^{-1}\right)$. The phosphate anomaly strongly increases in the beginning of 1984 and reaches its maximum of more than $0.15 \mu \mathrm{mol} \mathrm{L}-1$ in the fall of the same year. A strengthened upwelling of nutrient-rich water creates extremely good growth conditions and forces an increase of export production.

The anomaly of the $\delta^{13} \mathrm{C}$ isotope ratio in the surface layer of the ocean (Figure 9f) shows a striking increase of up to $0.3 \%$ due to a diminished influx of low $\delta^{13} \mathrm{C}$ upwelling water overcompensating the tendency for more negative values caused by the reduced export production. In the following years a general reduction in the equatorial $\delta^{13} \mathrm{C}$ ratio occurs through strengthened equatorial upwelling.

Figure 10 a shows a time latitude diagram along $1.25^{\circ} \mathrm{N}$ in the Pacific for 1982 and 1983 . The model simulates from summer 1982 to the following summer 1983 an area of strongly reduced upwelling in the central and western Pacific. The propagation of equatorial reflected Kelvin waves, as discussed, for example, by Latif [1987] with previous OGCM experiments, might be an explanation for the temporal evolution of the temperature anomalies, shown in Figure 10b. Starting in October 1982 a positive anomaly of $2^{\circ} \mathrm{C}$, produced by anoma- lies of the wind field, travels over the Pacific within a period of three months and generates in the eastern part an increase in the SST of more than $3^{\circ} \mathrm{C}$. The first signs of the subsequent La Niña are seen already during the winter of 1982/1983 in the western Pacific with an eastward extension of positive anomalies of more than $2 \mathrm{x}$ $10^{-6} \mathrm{~m} \mathrm{~s}^{-1}$.

The $\mathrm{pCO}_{2}$ differences between ocean and atmosphere are shown for the experiment run in Figure 10c. The structure is mainly determined by the vertical velocity. From fall 1982 to spring 1983 a large reduction of the $\mathrm{pCO}_{2}$ is observed over the entire equatorial Pacific with highest values of the anomaly in the east. The $\mathrm{pCO}_{2}$ difference starts to rise in the midwestern part of the ocean in April 1983 and a maximum, with over 100 $\mathrm{ppm}$ centered at $150^{\circ} \mathrm{W}$, is reached half a year later.

\section{Comparison of Model Results and Observations}

The model predicted atmospheric anomaly of the long-term $\mathrm{CO}_{2}$ growth rate is compared in Figure 11 with data after Keeling et al. [1989] (shown in Figure 1). The model results represent only the influence of the oceanic component to the atmospheric $\mathrm{CO}_{2}$ fluctuations, while the observations possibly include terrestrial effects as well. In 1982 the modeled anomaly is small

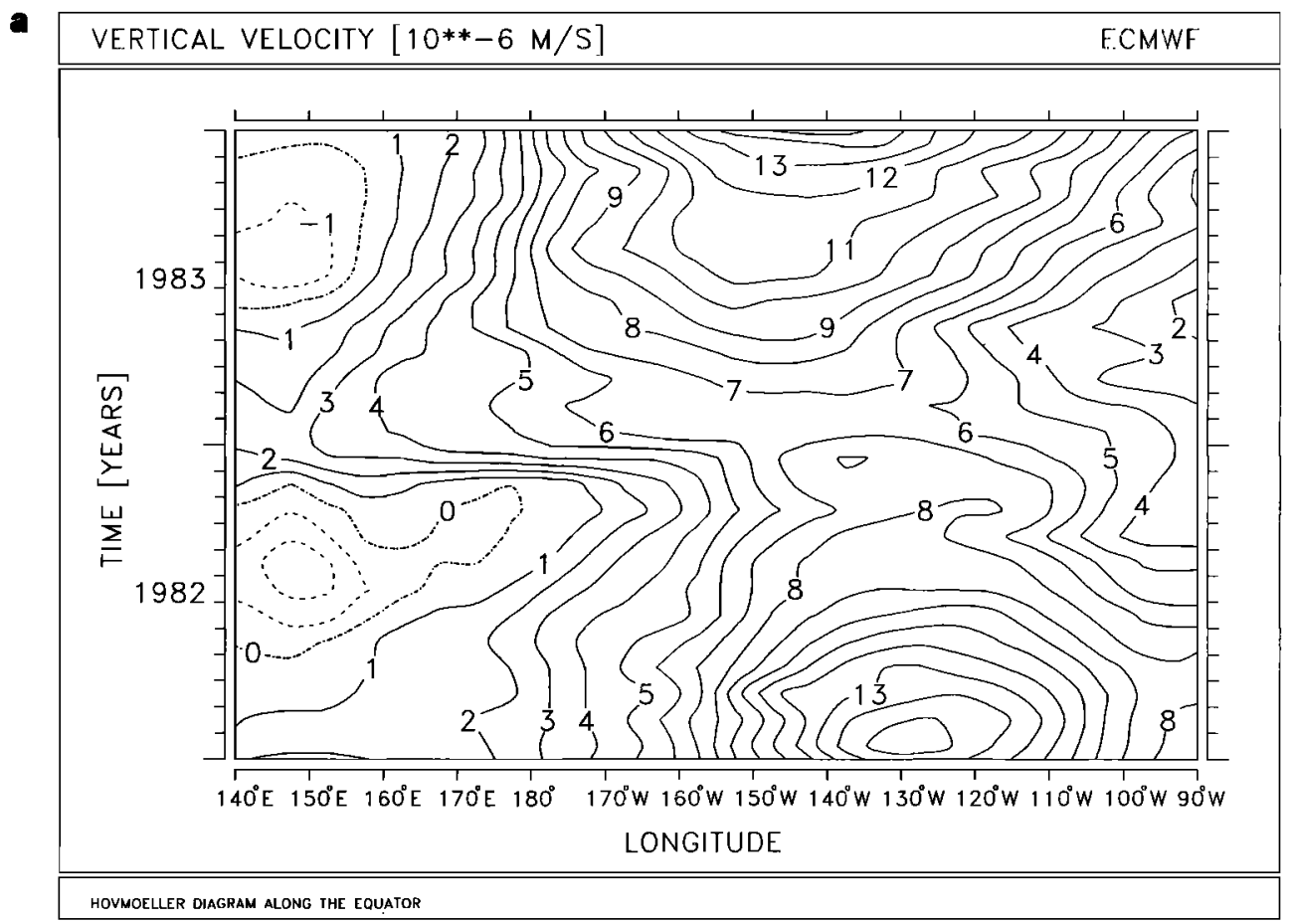

Figure 10. Time series in the Pacific along $1.25^{\circ} \mathrm{N}$ : (a) vertical velocity (experiment, between surface and second layer), (b) sea surface temperature (SST) anomaly (experiment minus control), and (c) $\Delta \mathrm{pCO}_{2}$ between ocean and atmosphere (experiment). 


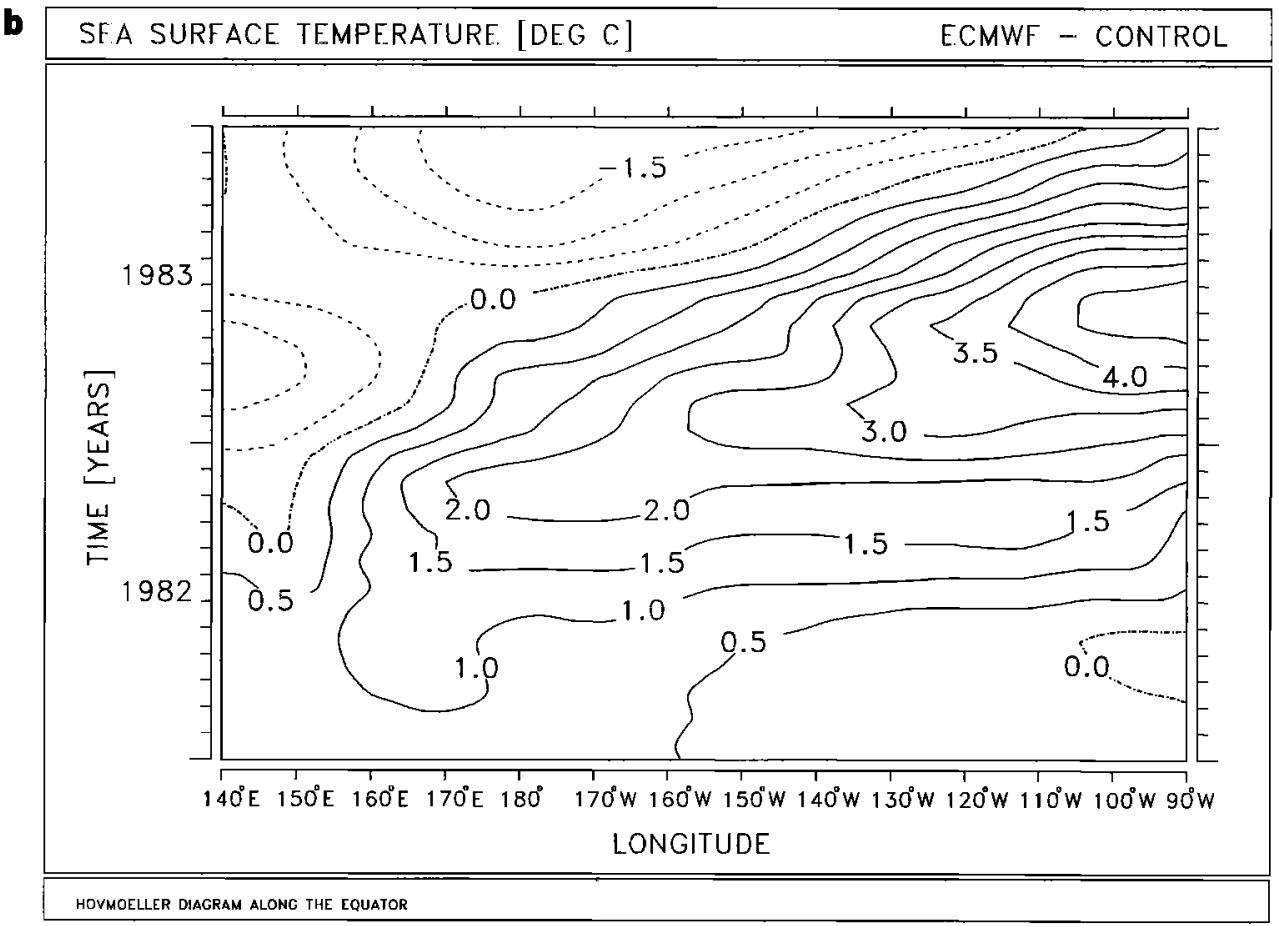

c

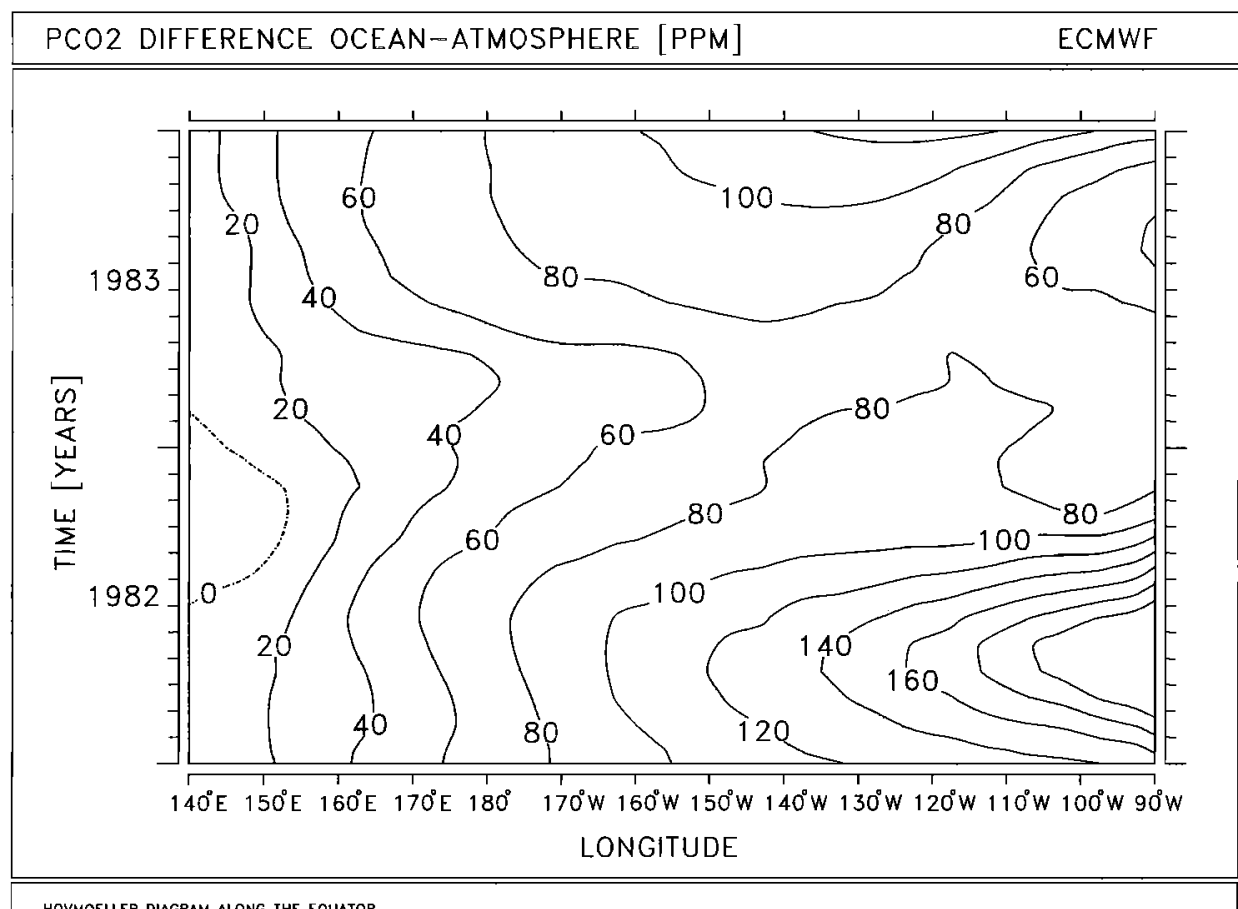

Fig. 10. (continued)

compared with the aata. As described in section 4 the model produces in early 1982 high $\Delta \mathrm{pCO}_{2}$ values in the Southern Ocean due to convective overturning forced by cold antarctic easterlies during that period, which might be unrealistic. The associated anomalously high- latitude $\mathrm{CO}_{2}$ influx masks in the global balance the reduced outgassing during 1982 . The model results show that the ocean is a carbon sink during ENSO events. In 1983 the model simulates a negative anomaly of the growth rate of $0.3 \mathrm{ppm} / \mathrm{yr}$. The observations after Keel- 


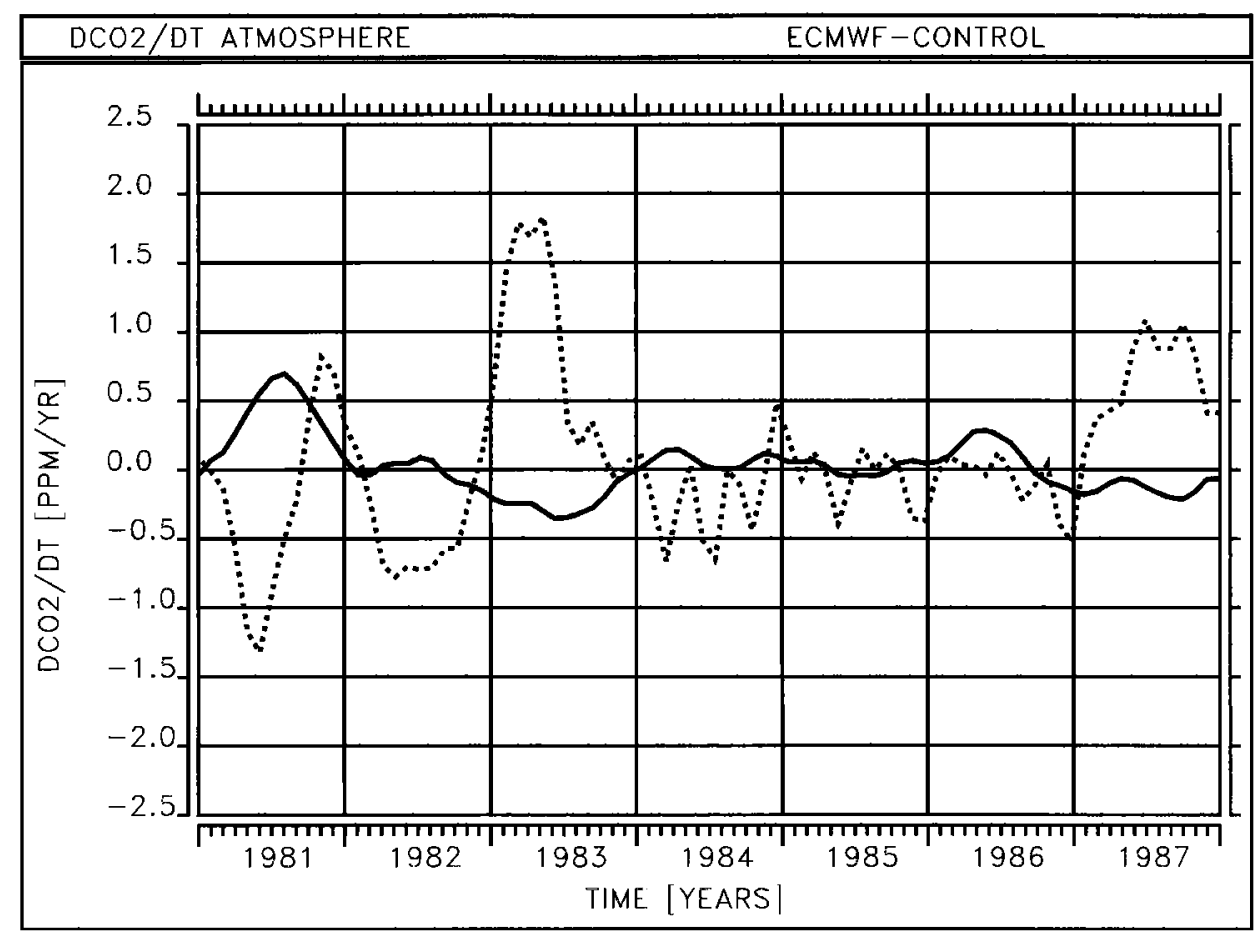

Figure 11. Time series of the 5 -month runing mean of the difference from the atmospheric $\mathrm{CO}_{2}$ growth rate between experiment and control run (solid) compared with the anomaly of the atmospheric $\mathrm{CO}_{2}$ growth rate after Keeling et al. [1989] (dashed) in Figure 1.

ing et al. show, however, during the entire year an increase of more than $0.7 \mathrm{ppm} / \mathrm{yr}$. The difference between the model predictions and the observations might be explained by a $\mathrm{CO}_{2}$ release from the terrestrial biosphere.

Time series of globally averaged $\delta^{13} \mathrm{C}$ differences between the experiment run and the control run (Figure 12) are shown in comparison with seasonally adjusted observations (Figure 2), averaged from measurements at the Mauna Loa Observatory and the South Pole [Keeling et al., 1989, p. 181]. The ocean indicates no significant changes in the atmospheric $\delta^{13} \mathrm{C}$ ratio (less than $0.01 \%$ ), despite the surface water $\delta^{13} \mathrm{C}$ excursion of more than $0.3 \%$. On the other hand, the observed isotopic shift in the atmosphere, peak to trough, is approximately $0.1 \%$. The difference between model results and observations confirms the suggestion of Keeling et al. [1989] that the 1983 peak in the anomaly of the $\mathrm{CO}_{2}$ is mainly induced by $\mathrm{CO}_{2}$ released from the terrestrial biosphere (with a low $\delta^{13} \mathrm{C}$ ratio of about $-25 \%$ ).

Figure 13 shows sea to air carbon flux anomalies (solid, bold) in relation to the sea surface temperature (SST) (dashed, bold) from the experiment averaged over the entire tropical Pacific from $20^{\circ} \mathrm{N}$ to $20^{\circ} \mathrm{S}$. Carbon flux and SST are inverse correlated in the experiment with a correlation coefficient $r$ of 0.8 where the temperature leads the $\mathrm{CO}_{2}$ flux with a time lag of approximately 4 months. An even higher correlation coefficient $(r>0.8)$ occurs in the region between $10^{\circ} \mathrm{N}$ and $10^{\circ} \mathrm{S}$. Maximal variations are observed during El Niño 1982/1983 for both curves in May 1983. The carbon fluxes from the ocean into the atmosphere are slightly decreased during the El Niño $1986 / 1988$, but a significant warming of the sea surface is not produced by the experiment (section 4). For comparison, global oceanic fluxes (solid, light) estimated from atmospheric $\mathrm{CO}_{2}$ and $\delta^{13} \mathrm{C}$ data [Keeling et al., 1989, p. 204] are also shown in Figure 13. Observed sea surface temperature anomalies (dashed, light) [Oort and Pan, 1986; Keeling et al., 1989, p. 204] are calculated from monthly average deviations of the long-term mean between 1950 and 1979 over the Eastern Equatorial Pacific (EEP). The time lag between the observed $\mathrm{CO}_{2}$ flux and the EEP-SST is about 6 months as deduced by Keeling et al. [1989, p. 204]. The lag between Keeling et al. fluxes and those from our model is about 5 months.

Figure 14a-14c shows meridional surface sections of $\mathrm{pCO}_{2}$ difference between ocean and atmosphere over the Central Pacific for the experiment in comparison with observations from Feely et al. [1987]. The observational data are evaluated from measurements of oceanic $\mathrm{pCO}_{2}$ from cruises during spring 1983 and spring 1984. The general structures are in good agreement, with a reduction of the amplitude during spring 1983 (El Niño) and an increased flux from the ocean into the atmosphere in spring 1984 (La Niña). Because of the coarse resolution of the model, the simulated amplitudes and 


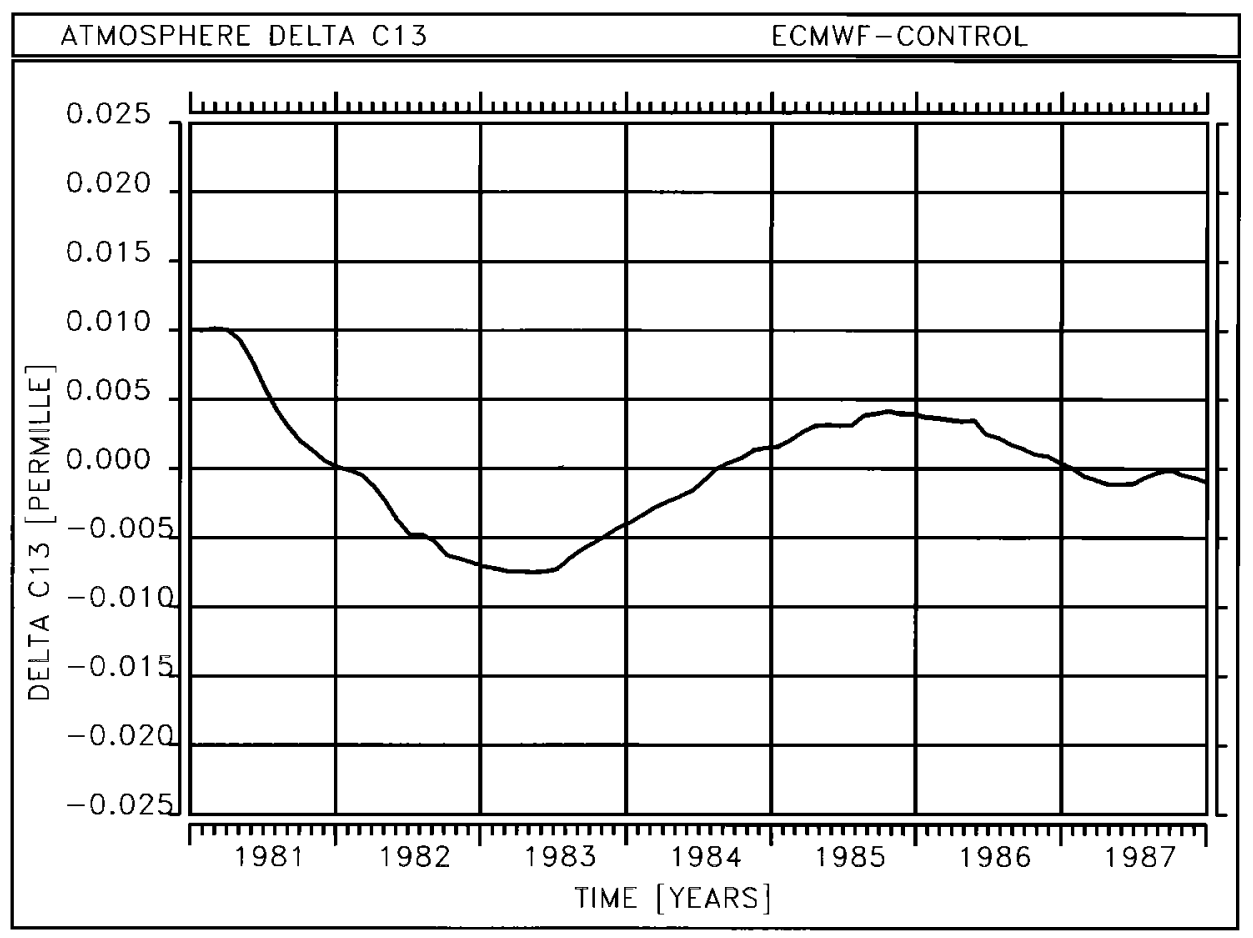

Figure 12. Time series of interannual fluctuations of the global atmospheric $\delta^{13} \mathrm{C}$ in $\%$ : model results from experiment minus control run.

horizontal structures of the oceanic $\mathrm{pCO}_{2}$ are weaker and less pronounced than in the observations.

The difference of $\mathrm{pCO}_{2}$ between ocean and atmosphere of the experiment are higher than the observed values possibly due to the strong equatorial upwelling in the model that is slightly overestimated. Differences for phosphate concentrations, shown as April 1984 minus April 1983, for the experiment and for the observations [after Feely et al:, 1987] are demonstrated in Figure 14d. The observational anomaly was calculated by averaging the two sections from March 1984 at $150^{\circ} \mathrm{W}$ and April 1984 at $170^{\circ} \mathrm{W}$. These values were subtracted from the measurements in April 1983 at $158^{\circ} \mathrm{W}$. Model results and observations show both a significant reduction of the nutrients during the El Niño 1982/1983.

\section{Summary and Conclusions}

For sensitivity studies we investigated the impact of interannual climate fluctuations, such as El Niño events, on the oceanic carbon cycle. The influence of the oceanic carbon cycle on changes in the interannual atmospheric $\mathrm{CO}_{2}$ record has been discussed in previous studies, based on direct measurements [e.g., Feely et al., 1987; Keeling et al., 1989; Inoue and Sugimura, 1992; Wong et al., 1993] or calculations with box models [e.g., Volk, 1989; Siegenthaler, 1990]. In this article we presented an experiment with a three-dimensional ocean circulation model (Hamburg LSG) coupled on-line with a oceanic carbon cycle model (HAMOCC-3) perturbed by anomalies from observed wind and 2-m air temperatures analyzed for 1981-1987 at the European Center of Medium Range Weather Forecasts.

During the El Niño 1982/1983 the ocean model predicted a decrease of oceanic $\mathrm{pCO}_{2}$ in the eastern equatorial Pacific partly by more than 100 ppm (Figure 8 ). This decrease is caused by a reduced upwelling of cold carbon-rich water into the uppermost layer. Opposing effects that lead to an increase of oceanic $\mathrm{pCO}_{2}$, like warming of the surface layer and a decrease of nutrients, are smaller than the upwelling effect. The significant decrease in 1982 of the observed interannual $\mathrm{CO}_{2}$ flux anomalies (Figure 1) can be produced by the model for the tropics (Figure 13), lagged to the SOI by approximately 5 months. The three-dimensional model predictions for 1982 are supported by results from a five-box model [Winguth, 1992] which was forced from 1981 to 1987 in the tropics by ECMWF wind field anomalies. In higher latitudes, model results which show strong positive anomalies in 1981 and 1982 must be treated carefully due to possibly overestimated convective overturning.

We have essentially confirmed previous work with three- and five-box models by Volk [1989]. The main differences between ours and his findings may be attributed to the different initial and boundary conditions of the models and to the different model behavior during the first years of the experiments. The result supports 


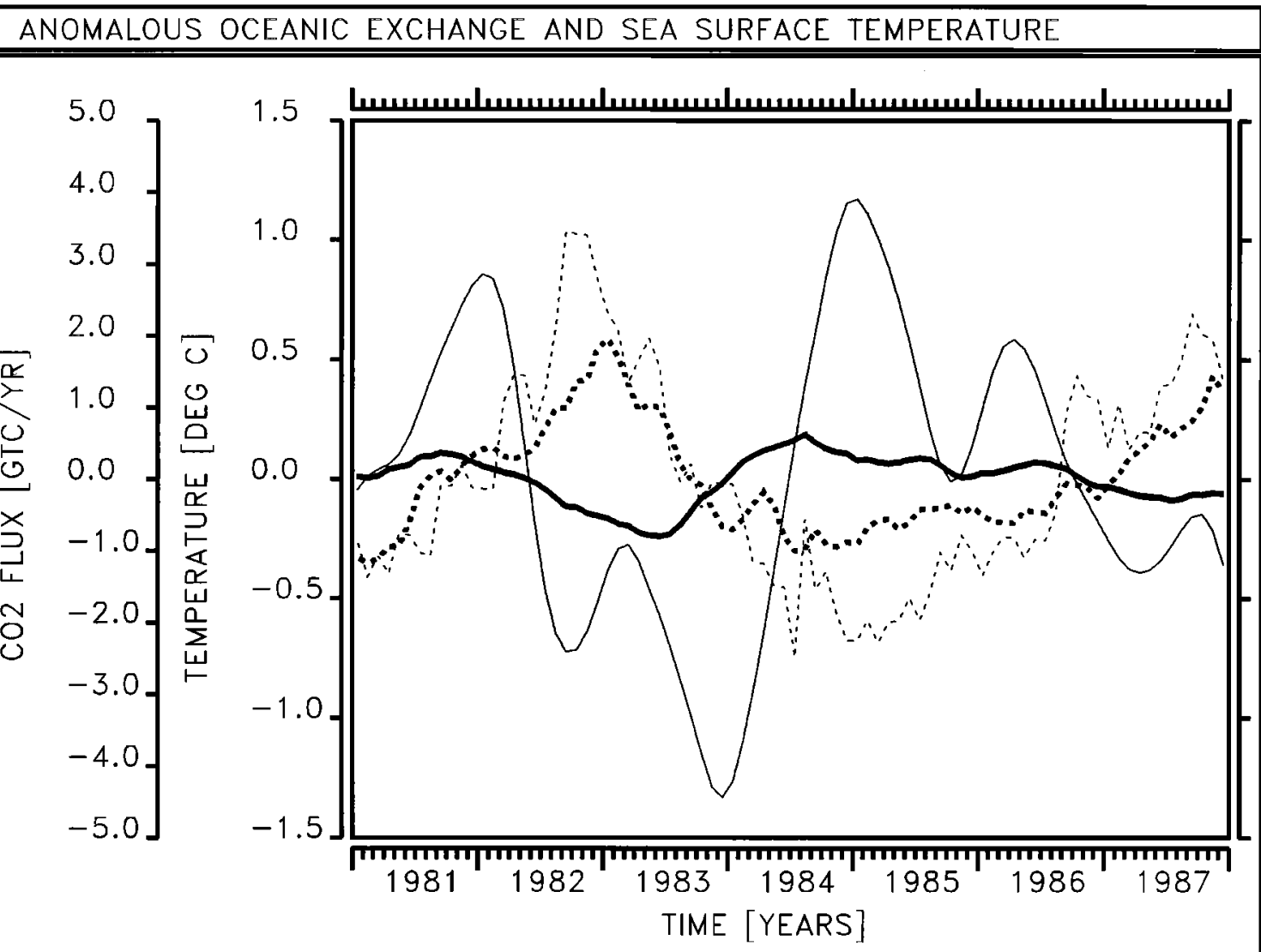

Figure 13. Time series of sea surface temperature anomaly in degree celsius (solid, bold) and carbon flux anomaly between ocean and atmosphere in $\mathrm{GtC} \mathrm{yr}^{-1}$ (dashed, bold) from experiment, averaged between $20^{\circ} \mathrm{N}$ and $20^{\circ} \mathrm{S}$ over the entire Pacific compared with observed SST anomaly (dashed, light) [Oort and Pan, 1986] in the eastern equatorial Pacific (averaged over the region between $20^{\circ} \mathrm{N}$ and $20^{\circ} \mathrm{S}$ from $180^{\circ} \mathrm{W}$ to $80^{\circ} \mathrm{W}$ ) and global carbon fluxes (solid, light), estimated from atmospheric $\mathrm{CO}_{2}$ and $\delta^{13} \mathrm{C}$ data [Keeling et al., 1989].

also previous studies, suggesting enhanced $\mathrm{CO}_{2}$ uptake by the oceans during ENSO events [Keeling and Revelle, 1985; Keeling et al., 1989].

We estimated from our model results an anomalous decline of atmospheric $\mathrm{CO}_{2}\left(\delta C_{0}\right)$, which is caused by the ocean in 1983 , of approximately $-0.6 \mathrm{GtC}$ corresponding to $-0.3 \mathrm{ppm}$ (Figure 11). The observed atmospheric $\mathrm{CO}_{2}\left(\delta C_{a}\right)$ increase by more than $1.4 \mathrm{GtC}$ $(0.7 \mathrm{ppm})[$ Keeling et al., 1989] has the opposite sign but includes both oceanic and land biosphere effects. Our results confirm that the atmospheric $\delta^{13} \mathrm{C}$ changes caused by the ocean (Figure 12) during the El Niño are small compared to the changes observed by Keeling et al. (Figure 2). The differences between the observed and modeled $\mathrm{CO}_{2}$ and $\delta^{13} \mathrm{C}$ values in the atmosphere might be explained by a $\mathrm{CO}_{2}$ release from the terrestrial biosphere with low $\delta^{13} \mathrm{C}$ values. From our results we conclude that the release of $\mathrm{CO}_{2}$ from the land biosphere $\left(\delta C_{b}=\delta C_{a}-\delta C_{o}\right)$ must have been approximately +2 GtC corresponding to $1 \mathrm{ppm}$ in 1983 which is $0.6 \mathrm{GtC}$ higher than the observed changes in the atmosphere of $1.4 \mathrm{GtC}$. However, the model predicted anomalous decline to the ocean of $-0.6 \mathrm{GtC}$ is substantially smaller than the -4 GtC shift inferred by Keeling et al. [1989] based on atmospheric observations of $\mathrm{CO}_{2}$ and $\delta^{13} \mathrm{C}$ alone (Figure 13). Whether this discrepancy reflects a too week sensitivity of the HAMOCC-3 to climate fluctuations or a possible overestimate in the analysis of Keeling et al. [1989], which depends crucially on the small atmospheric $\delta^{13} \mathrm{C}$ data, is impossible to decide on this stage.

Improved analysis of observed wind and temperature fields would possibly lead, especially in higher latitudes, to a more realistic model simulation. Furthermore, similar sensitivity experiments including an atmospheric transport model and a land biosphere model could improve our understanding of interactions between the carbon cycle and climate fluctuations on the ENSO timescale. 
?

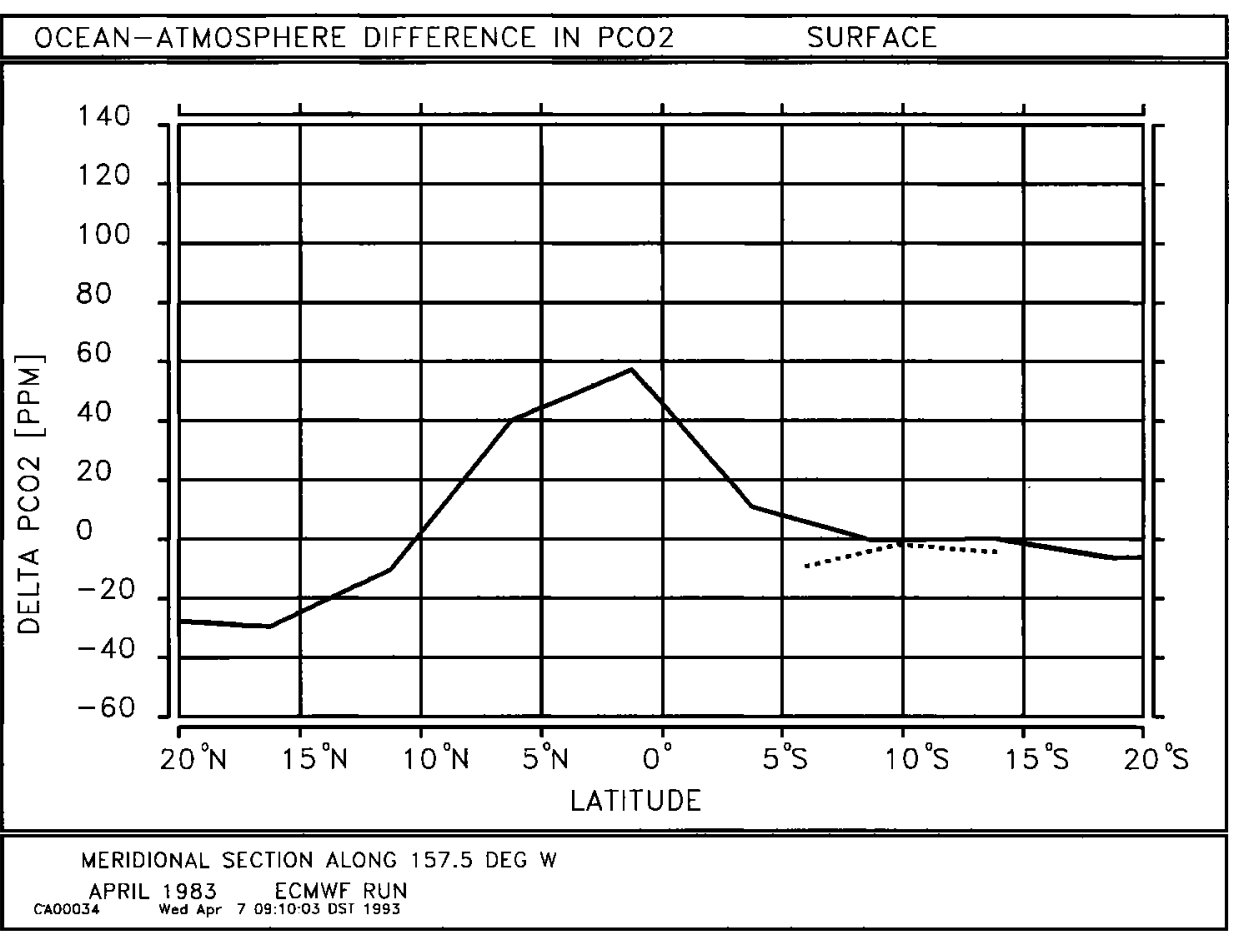

b

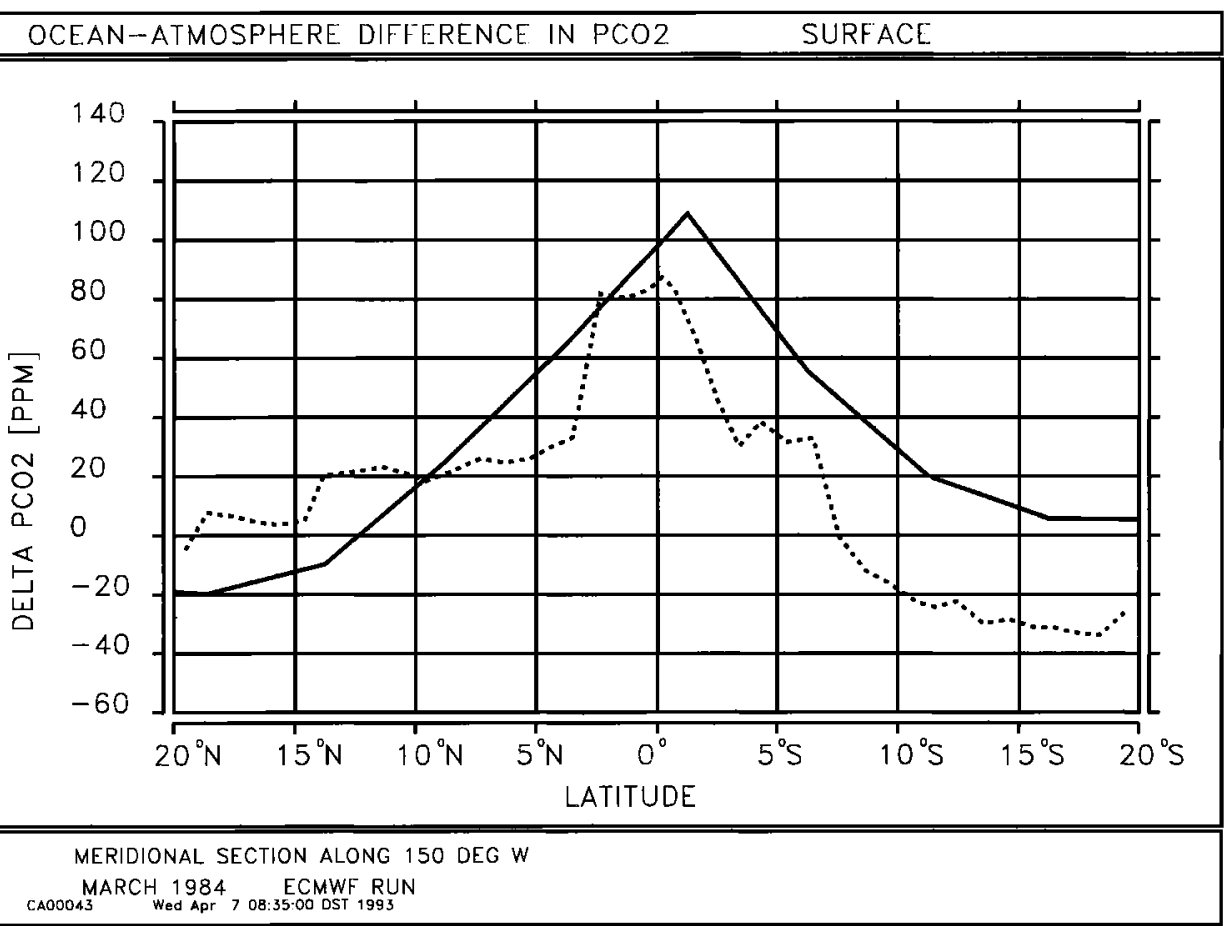

Figure 14. Surface sections over the Pacific between $20^{\circ} \mathrm{N}$ and $20^{\circ} \mathrm{S}$ from the experiment (solid), and observations (dashed) [after Feely et al., 1987]: (a) difference of partial pressure $\mathrm{pCO}_{2}$ between ocean and atmosphere at $157.5^{\circ} \mathrm{W}$ in April 1983, (b) difference of partial pressure $\mathrm{pCO}_{2}$ between ocean and atmosphere at $150^{\circ} \mathrm{W}$ in March 1984, (c) difference of partial pressure $\mathrm{pCO}_{2}$ between ocean and atmosphere at $170^{\circ} \mathrm{W}$ in April 1984, and (d) phosphate differences of April 1984 minus April 1983 at $157.5^{\circ} \mathrm{W}$. 


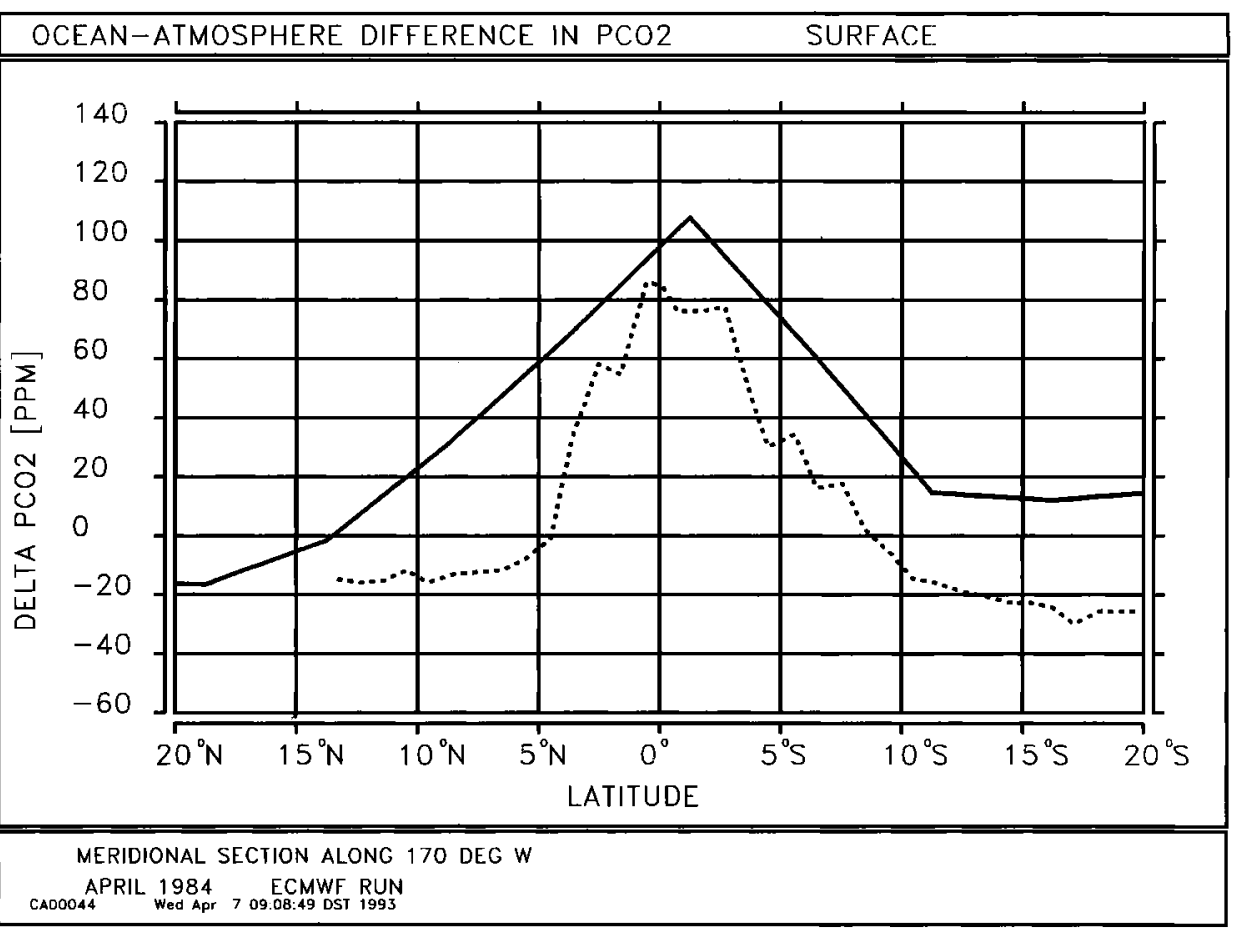

\begin{tabular}{ll}
\hline PHOSPHATE & SURFACE \\
\hline
\end{tabular}

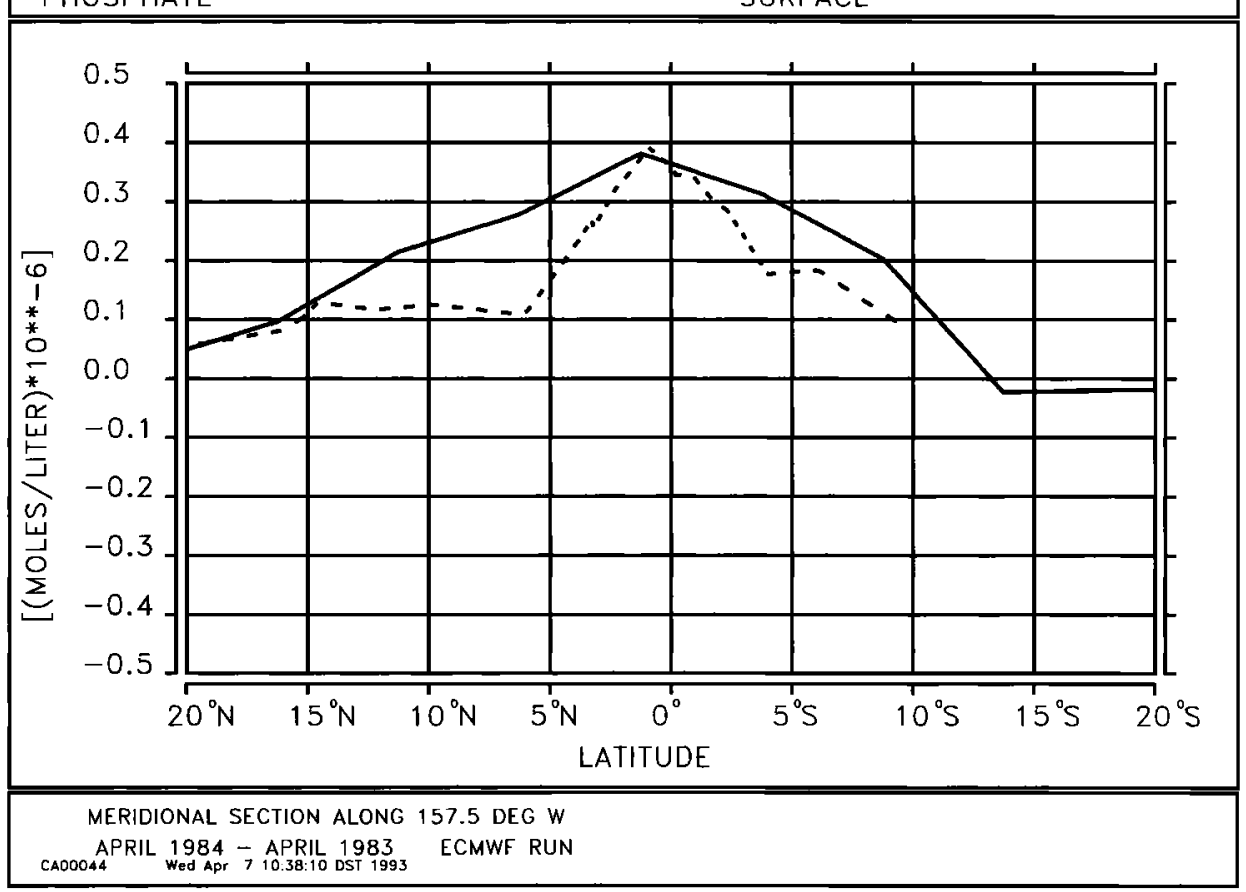

Fig. 14. (continued) 
Acknowledgments. We thank both reviewers Stephen C. Piper and Tyler Volk for fruitful discussions and helpful ideas. Thanks also to Wolfgang Knorr for useful reviewing of an earlier version of this article, and Marion Grunert, Heinke Höck and Norbert Noreiks for the graphics. The work at the Max-Planck-Institut was supported by the Commission of the European Community (EPOC-CT90-0017) and the Körber Project.

\section{References}

Arakawa, A., and V.R. Lamb, Computational design of the basic dynamical processes of the UCLA general circulation model, Methods Comput. Phys., 16, 173-283, 1977.

Bacastow, R., Modulation of atmospheric carbon dioxide by the southern oscillation, Nature, 261, 116, 1976.

Bacastow, R., J.A. Adams, C.D. Keeling, D.J. Moss, T.P. Whorf, and C.S. Wong, Response of atmospheric carbon dioxide to the weak $1975 \mathrm{El}$ Niño, Science, 210,110, 1980.

Bainbridge, A.E., GEOSECS Atlantic Ocean: Final hydrographic data report, GEOSECS Operations Group/Nat. Sci. Found., Washington, D. C., 1975.

Bainbridge, A.E., GEOSECS Pacific Ocean: Final hydrographic data report, GEOSECS Operations Group/Nat. Sci. Found., Washington, D. C., 1976.

Bengtsson, L., M. Kanamitsu, P. Kallberg, and S. Uppala, FGGE 4-dimensional data assimilation at ECMWF, Bull. Am. Meteorol. Soc., 63, 29-43, 1982.

Berger, W.H., K. Fischer, C. Lai, and G. Wu, Ocean productivity and organic carbon flux, SIO Ref. 87-30, Scripps Inst. of Oceanogr., La Jolla, Calif., 1987.

Broecker, W.S., and E. Maier-Reimer, The influence of air and sea exchange on the carbon isotope distribution in the sea, Global Biogeochem. Cycles, 6, 315-320, 1992.

Broecker, W.S., and T.-H. Peng (Eds.), Tracers in the Sea, 690 pp., Eldigio, Palisades, N. Y., 1982.

Broecker, W.S., J.R. Ledwell, T. Takahashi, R. Weiss, L. Merlivat, L. Memery, T.-H. Peng, B. Jähne, and K.O. Münnich, Isotopic versus micrometeorologic ocean $\mathrm{CO}_{2}$ fluxes: A serious conflict, J. Geophys. Res., 91, 10,517$10,527,1986$

Chavez, F.B., R.T. Barber, J.E. Kogelschatz, V.G. Thayer, and B. Cai, El Niño and primary productivity: Potential effects on atmospheric carbon dioxide and fish production, Trop. Ocean Atmos. Newsl., 28, 1-2, 1984.

Degens, E.T., S. Kempe, and A. Spitzy, Carbon dioxide: A biochemical portrait, in The Handbook of Enviromental Chemistry, vol. 1, edited by C. O. Hutzinger, pp. 127-215, Springer, Berlin, Heidelberg, Germany, 1984.

Dietrich, G., K. Kalle, W. Krauss, and G. Siedler (Eds.), Allgemeine Meereskunde, 593 pp., Gebrüder Bornträger, Berlin, Stuttgart, Germany, 1975.

Dugdale, R.C., Nutrient limitation in the sea: Dynamics, identification and significance, Limnol. Oceanogr., 12, $685-695,1967$.

Eppley, R., and B.T. Peterson, Particulate organic matter flux and planktonic new production in the deep ocean, Nature, 282, 677-680, 1979.

Feely, R.A., R.H. Gammon, B.A. Taft, P.E. Pullen, L.E. Waterman, T.J. Conway, J.F. Gendron, and D.P. Wisegarer, Distribution of chemical tracers in the Eastern Equatorial Pacific during and after the 1982-1983 El-Niño Oscillation event, J. Geophys. Res., 92, 6545-6558, 1987.
Francey, R., F.J. Robbins, C.E. Allison, and N.G. Richards, 1. The CSIRO Global Survey of $\mathrm{CO}_{2}$ Stable Isotopes, in Baseline Atmospheric Program 88, edited by S. R. Wilson and G. P. Ayers, pp. 16-27, CSIRO/Division of Atmospheric Research, Australia, 1990

Friedli, H., H. Loetscher, U. Siegenthaler, and B. Stauffer, Ice core records of ${ }^{13} \mathrm{C} /{ }^{12} \mathrm{C}$ record of atmospheric $\mathrm{CO}_{2}$ in the past two centuries, Nature, 324, 237-238, 1986.

Gammon, R.H., E.T. Sundquist, and P.J. Fraser, History of carbon dioxide in the atmosphere, Atmospheric Carbon Dioxide and the Global Carbon Cycle, Rep. DOE/ER0239, U.S. Department of Energy, Washington, D. C., 1985.

Heimann, M., and P. Monfray, Spatial and temporal variation of the gas exchange coefficient for $\mathrm{CO}_{2}, 1$, Data analysis and global validation, Rep. 31, Max-Planck-Institut für Meteorolgie, Hamburg, Germany, 1991.

Heinze C., E. Maier-Reimer, and K. Winn, Glacial $\mathrm{pCO}_{2}$ reduction by the world ocean: Experiments with the Hamburg carbon cycle model, Paleoceanography, 6, 395-430, 1991.

Hellerman, S., and M. Rosenstein, Normal monthly wind stress over the world ocean with error estimates, J. Phys. Oceanogr., 13, 1093-1104, 1983.

Inoue, H.Y., and Y. Sugimura, Variations and distributions of $\mathrm{CO}_{2}$ in and over the equatorial Pacific during the period from the 1986/88 El Niño event to the 1988/89 La Niña event, Tellus, Ser. B, 44, 1-22, 1992.

Keeling, C.D., and R. Revelle, Effects of El Niño/Southern Oscillation on the atmospheric content of carbon dioxide, Meteoritics, 20(2), 437-450, 1985.

Keeling, C.D., R.B. Bacastow, A.F. Carter, S.C. Piper, T.P. Whorf, M. Heimann, W.G. Mook, and H. Roeloffzen, A three-dimensional model of atmospheric $\mathrm{CO}_{2}$ transport based on observed winds, 1 , analysis of observational data, in Aspects of Climate Variability in the Pacific and the Western Americas, Geophys. Monogr. Ser., vol. 55, edited by D. H. Peterson, pp. 165-236, AGU, Washington, D. C., 1989.

Kurz, K.D., and E. Maier-Reimer, Iron fertilization of the austral ocean - A Hamburg model assessment, Global Biogeochem. Cycles, 7, 229-244, 1993.

Latif, M., Tropical Ocean Circulation Experiments, J. Phys. Oceanogr., 17, 246-263, 1987.

Levitus, S., Climatological Atlas of the World Ocean, Prof. Pap., 13, National Oceanic and Atmospheric Administration, Rockville, Md., 1982.

Liss, P.S., and L. Merlivat, Air-sea gas exchange rates: Introduction and synthesis, in The Role of Air-Sea Exchange in Geochemical Cycling, edited by P. Buat-Ménard, pp. 113-127, D. Reidel, Norwell, Mass., 1986.

Machta, L., K.T. Hanson, and C.D. Keeling, in The Fate of Fossil Fuel $\mathrm{CO}_{2}$ in the Oceans, edited by N. R. Anderson and A. Malahoff, pp. 131-143, Plenum, New York, 1977.

Maier-Reimer, E., Geochemical cycles in an ocean general circulation model. Preindustrial tracer distributions, Global Biogeochem. Cycles, 7, 645-677, 1993.

Maier-Reimer, E., U. Mikolajewicz, and K. Hasselmann, Mean circulation of the Hamburg LSG OGCM and its sensitivity to the thermohaline surface forcing, $J$. Phys. Oceanogr., 23, 731-757, 1993.

Mikolajewicz, U., and E. Maier-Reimer, Internal secular variability in an ocean general circulation model, Clim. Dyn., 4, 145-156, 1990.

Mook, W.G., J.C. Bommerson, and W.H. Staverman, Carbonate isotope fractionation between dissolved bicarbon- 
ate and gaseous carbon dioxide, Earth Planet. Sci. Lett, 22, 169-176, 1974.

Newell, R.E., A.R. Navato, and J. Hsiung, Longterm global sea surface temperature fluctuations and their possible influence on atmospheric $\mathrm{CO}_{2}$ concentrations, Pure Appl. Geophys., 116, 351-371, 1978.

Oort, A.H., and Y.H. Pan, Diagnosis of historical ENSOevents, in Proceedings of the First WMO Workshop on the Diagnosis and Prediction of Monthly and Seasonal Atmospheric Variations Over the Globe, WMO/TD, pp. 249-258, 87, World Meteorological Organization, Geneva, 1986.

Pan, Y.H., and A.H. Oort, Correlation analysis between sea surface temperature anomalies in the eastern equatorial Pacific and the world ocean, Clim. Dyn., 4, 191-205, 1990.

Philander, S.G., El Niño, La Niña, and the Southern Oscillation, 293 pp., Academic, San Diego, Calif., 1990.

Rasmusson, E.M., and M. Hall, Warming Event of 1982 1983, Weatherwise, 36, 164-175, 1983.

Rasmusson, E.M., and J.M. Wallace, Meteorological aspects of the El Niño/Southern Oscillation, Science, 222, 11951202, 1983.

Reynolds, R.W., A real time global sea surface temperature analysis, J. Clim., 1, 75-86, 1988.

Reynolds, R.W., K. Arpe, C. Gordon, S. Hayes, A. Leetmaa, and M.J. McPhaden, A comparison of tropical Pacific surface wind analyses, J. Clim., 2, 105-11, 1989.

Segschneider, J., Windinduzierte Variabilität in der Warmwassersphäre von 1981-1987, Teil I, Datenaufbereitung und SST, Diplomarbeit Fach Ozeanogr., Univ. of Hamburg, Hamburg, Germany, 1991.

Shaw, D.B., P. Lönnberg, A. Hollingsworth, and P. Uden, Data assimilation: The 1984/85 revisions of the ECMWF assimilation system, Q. J.R. Meteorol. Soc., 113, 10481066, 1987.

Siegenthaler, U., and T. Wenk, Modelling the ocean's role for El Niño-related $\mathrm{CO}_{2}$ variations, in Abstracts of the Third International Conference on Analysis and Evaluation of Atmospheric $\mathrm{CO}_{2}$ Data Present and Past, Hinterzarten, vol. 59, pp. 189-194, World Meteorological Organization, Geneva, 1989.
Siegenthaler, U., El Niño and atmospheric $\mathrm{CO}_{2}$, Nature, 345, 295-296, 1990.

Trenberth, K.E., W.L. Large, and J.G. Olson, The effective drag coefficient for evaluating wind stress over the oceans, J. Clim., 2, 1507-1516, 1989.

Volk, T., Effect of the equatorial Pacific upwelling on atmospheric $\mathrm{CO}_{2}$ during the $1982-1983$ El Niño, Global Biogeochem. Cycles, 3, 267-279, 1989.

Winguth, A.M.E., Windinduzierte Variabilität in der Warmwassersphäre von 1981-1987, Teil II, Fluktuationen im Kohlenstoffkreislauf, Examensarbeit 14, Max-Planck-Institut für Meteorologie, Hamburg, Germany, 1992.

Wong, C.S., Y.-H. Chan, J.S. Page, G.E. Smith, and R.D. Bellegay, Changes in equatorial $\mathrm{CO}_{2}$ flux and new production estimated from $\mathrm{CO}_{2}$ and nutrient levels in Pacific surface waters during the $1986 / 87 \mathrm{El}$ Niño, Tellus, Ser. $B, 45,64-79,1993$.

Woodruff, S.D., R.J. Slutz, R.L. Jenne, and P.M. Steurer, A comprehensive ocean-atmosphere data set, Bull. Am. Meteorol. Soc., 68, 1239-1250, 1987.

Wright, P.W., Relationships between indices of the Southern Oscillation, Monthly Weather Rev., 112, 1913-1919, 1984.

Wyrtki, K., E. Firing, D. Halpern, R. Knox, G.J. McNally, W.C. Patzert, E.D. Stroup, B.A. Traft, and R. Williams, The Hawaii to Tahiti Shuttle Experiment, Science, 211, 22-28, 1981.

M. Heimann, K. D. Kurz, E. Maier-Reimer, U. Mikolajewicz, and J. Segschneider, and A. M. E. Winguth, Max-Planck-Institut für Meteorologie, Bundesstrasse 55, D-20146 Hamburg, Germany.

(e-mail: heimann@dkrz.d400.de, kurz@dkrz.d400.de, maierreimer@dkrz.d400.de, mikolajewicz@dkrz.d400.de, segschneider@dkrz.d400.de, winguth@dkrz.d400.de)

(Received May 5, 1993; revised October 29, 1993; accepted November 4, 1993.) 